\title{
Impact of Cytoplasmic Calcium Buffering on the Spatial and Temporal Characteristics of Intercellular Calcium Signals in Astrocytes
}

\author{
Zhong Wang, ${ }^{1}$ Michael Tymianski, ${ }^{2}$ Owen T. Jones, ${ }^{2}$ and Maiken Nedergaard ${ }^{1}$ \\ 1 Departments of Cell Biology and Anatomy and Neurosurgery, New York Medical College, Valhalla, New York 10595, and \\ 2Playfair Neuroscience Unit, University of Toronto, The Toronto Hospital-Western Division, Toronto, Ontario, \\ Canada M5T-2S8
}

\begin{abstract}
The impact of calcium buffering on the initiation and propagation of mechanically elicited intercellular $\mathrm{Ca}^{2+}$ waves was studied using astrocytes loaded with different exogenous, cell membrane-permeant $\mathrm{Ca}^{2+}$ chelators and a laser scanning confocal or video fluorescence microscope. Using an ELISA with a novel antibody to BAPTA, we showed that different cellpermeant chelators, when applied at the same concentrations, accumulate to the same degree inside the cells. Loading cultures with BAPTA, a high $\mathrm{Ca}^{2+}$ affinity chelator, almost completely blocked calcium wave occurrence. Chelators having lower $\mathrm{Ca}^{2+}$ affinities had lesser affects, as shown in their attenuation of both the radius of spread and propagation velocity of the $\mathrm{Ca}^{2+}$ wave. The chelators blocked the process of wave propagation, not initiation, because large $\left[\mathrm{Ca}^{2+}\right]_{i}$ increases elicited in the mechanically stimulated cell were insufficient to
\end{abstract}

trigger the wave in the presence of high $\mathrm{Ca}^{2+}$ affinity buffers. Wave attenuation was a function of cytoplasmic $\mathrm{Ca}^{2+}$ buffering capacity; i.e., loading increasing concentrations of low $\mathrm{Ca}^{2+}$ affinity buffers mimicked the effects of lesser quantities of highaffinity chelators. In chelator-treated astrocytes, changes in calcium wave properties were independent of the $\mathrm{Ca}^{2+}$ binding rate constants of the chelators, of chelation of other ions such as $\mathrm{Zn}^{2+}$, and of effects on gap junction function. Slowing of the wave could be completely accounted for by the slowing of $\mathrm{Ca}^{2+}$ ion diffusion within the cytoplasm of individual astrocytes. The data obtained suggest that alterations in $\mathrm{Ca}^{2+}$ buffering may provide a potent mechanism by which the localized spread of astrocytic $\mathrm{Ca}^{2+}$ signals is controlled.

Key words: calcium buffering; astrocytes; calcium chelators; BAPTA; calcium waves; cell culture; digital imaging
Waves of elevated cytosolic calcium that travel both within individual astrocytes as well as between them constitute a newly discovered form of nonsynaptic long-range signaling in the brain (Cornell-Bell et al., 1990). This signaling activity is not restricted to astrocytes, because it was recently found to modulate (Nedergaard, 1994) and be modulated by neuronal and axonal activity (Dani et al., 1992; Kriegler and Chiu, 1993; Murphy et al., 1993). Consequently, these findings have transformed the classical view of astrocytes from that of passive, structural, and supportive cells to one in which these cells may actively participate in information processing and, hence, in brain functioning (Nedergaard, 1994; Parpura et al., 1994).

The precise mechanisms governing the initiation and propagation of astrocytic $\mathrm{Ca}^{2+}$ waves are not completely understood. Experimental studies have shown that intercellular wave propagation is critically dependent on the coupling of adjoining astrocytes by functional gap junctions, because the waves are easily aborted by gap junction blockers such as halothane and octanol (Nedergaard, 1994; Steinhardt et al., 1994). The constant velocity

Received Feb. 14, 1997; revised June 19, 1997; accepted July 11, 1997.

This work was supported by an Ontario Technology Fund grant in collaboration with Allelix Biopharmaceuticals (M.T.) and National Institute of Neurological Diseases and Stroke Grants RO130007 and RO135011 (M.N.). M.T. is a Clinician Scientist of the Medical Research Council of Canada. M.N. is an established investigator of the American Heart Association. Z.W. and M.T. contributed equally to this study. We thank Artemis Khatcherian, Lili He, and Rita Sattler for technica assistence with cell cultures, Geula Bernstein for technical assistance with the immunohistochemistry, and Earl Bueno for graphics.

Correspondence should be addressed to Dr. Maiken Nedergaard, Department of Cell Biology and Anatomy, New York Medical College, Valhalla, NY 10595.

Copyright (C) 1997 Society for Neuroscience 0270-6474/97/177359-13\$05.00/0 of the waves suggests that their production involves a short-range autocatalytic reaction rather than the long-range diffusion of $\mathrm{Ca}^{2+}$ ions. One model suggests that $\mathrm{Ca}^{2+}$ wave propagation is achieved via a regenerative interaction between calcium ion concentration and the release of additional $\mathrm{Ca}^{2+}$ from internal stores (calcium-induced calcium release). Another model suggests that inositol 1,4,5-triphosphate $\left(\mathrm{IP}_{3}\right)$, a cytosolic second messenger that releases $\mathrm{Ca}^{2+}$ ions from intracellular stores, causes a rise in the free cytoplasmic calcium concentration $\left(\left[\mathrm{Ca}^{2+}\right]_{\mathrm{i}}\right)$ that generates additional $\mathrm{IP}_{3}$ through the activation of phospholipase $\mathrm{C}$ (Meyer, 1991; Berridge, 1993; Rooney and Thomas, 1993; Sneyd et al., 1995). It is currently unknown whether it is $\mathrm{IP}_{3}$ or $\mathrm{Ca}^{2+}$ ions that diff use across gap junctions to mediate the intercellular spread of the wave.

Astrocytic $\mathrm{Ca}^{2+}$ waves seldom travel further than a few hundred micrometers and terminate spontaneously despite the existence of a regenerative mechanism to perpetuate their spread. The factors governing their propagation distance, velocity, and mechanism of termination are not understood, despite the fact that these parameters may well be crucial to the physiological consequences of this newly discovered form of intercellular communication. Because $\mathrm{Ca}^{2+}$ waves are dependent on the diffusion of $\mathrm{Ca}^{2+}$ ions both within and possibly between the cells, we hypothesized that modulating $\mathrm{Ca}^{2+}$ ion diff usion may predictably alter the spatial and temporal character of the $\mathrm{Ca}^{2+}$ wave. To this end, we studied calcium waves in cultured astrocyte monolayers exposed to a range of cell-permeant, selective calcium-buffering agents having a variety of $\mathrm{Ca}^{2+}$ affinities, binding kinetics, and structures. Our data illustrate the marked dependence of astro- 
cytic $\mathrm{Ca}^{2+}$ signaling on $\mathrm{Ca}^{2+}$ buffering. This effect is a function of both the $\mathrm{Ca}^{2+}$ affinity and the quantity of the exogenous buffer and occurs without affecting gap junctions. This is the first report to illustrate directly that cytoplasmic calcium buffering constitutes an important and powerful mechanism for modulating astrocytic $\mathrm{Ca}^{2+}$ waves and may have implications for brain functioning in diseases such as brain injury, stroke, and epilepsy.

\section{MATERIALS AND METHODS}

Cell culture. Primary cultures of mixed glial cells and neurons were prepared from the forebrains of embryonic day 15-17 fetal rats using a modified version of standard techniques (Nedergaard et al., 1991). Briefly, 10-12 embryos were removed from pregnant rats anesthetized with pentobarbital $(50 \mathrm{mg} / \mathrm{kg}$; Anpro Pharmaceutical) and decapitated, and the forebrains were dissected out and immersed in $\mathrm{Ca}^{2+}$ - and $\mathrm{Mg}^{2+}$-free HBSS at $37^{\circ} \mathrm{C}$. An equal volume of $0.25 \%$ trypsin was added, and the tissue was trituated through a fire-polished Pasteur pipette, incubated at $37^{\circ} \mathrm{C}$ for $10 \mathrm{~min}$, and retriturated to homogeneity. An equal volume of culture medium was added, and the cell suspension was centrifuged for $10 \mathrm{~min}$ at $1000 \mathrm{rpm}$. After decanting, the pellet was diluted in $2 \mathrm{ml}$ of warm medium. A total of $8 \times 10^{5}$ cells were plated on poly-L-lysine- and fibronectin-coated $\left(1.2 \mu \mathrm{g} / \mathrm{cm}^{2}\right) 35 \mathrm{~mm}$ Corning (Corning, NY) dishes. The cultures were kept at $37^{\circ} \mathrm{C}$ in $5 \% \mathrm{CO}_{2}$ humidified air. The culture medium contained $10 \%$ fetal calf serum and $90 \%$ of an equal mixture of DMEM and F-12, supplemented with 8 $\mathrm{mg} / \mathrm{ml}$ D-glucose, $5 \mu \mathrm{g} / \mathrm{ml}$ insulin, $20 \mathrm{U} / \mathrm{ml}$ penicillin-G, $20 \mathrm{mg} / \mathrm{ml} \mathrm{strep-}$ tomycin, and $50 \mathrm{ng} / \mathrm{ml}$ amphotericin. Media were added, but not removed, every third day. Cultures were used for experiments $14-21 \mathrm{~d}$ after plating. Neuron-free or sparse areas were selected for recordings.

Drugs and experimental solutions. All experiments were performed in HBSS (catalog \#24020-067; Life Technologies, Gaithersburg, MD) containing $1.5 \mathrm{mM} \mathrm{Ca}^{2+}$ and $1.5 \mathrm{mM} \mathrm{Mg}^{2+}$, supplemented with HEPES $(25 \mathrm{~mm})$ and D-glucose (10 mM), $\mathrm{pH}$ 7.3. One-half hour before use, desiccated fluo-3 AM and fura-2 AM (Molcular Probes, Eugene, OR) were dissolved to $5 \mathrm{~mm}$ stocks in dimethylsulfoxide (DMSO). Stock solutions (30 mM) of BAPTA AM, dimethyl-BAPTA AM, 5,5'-difluoro-BAPTA AM, 5,5'-dibromo-BAPTA AM, 5-fluoro-4-methyl-2-aminophenol- $N, N, O$ triacetic acid (5F,4M-APTRA) AM, 5,5'-dinitro-BAPTA, EGTA AM, and tetrakis(2-pyridylmethyl)ethylenediaminea (TPEN) were also prepared in DMSO as above, aliquoted, and stored at $-20^{\circ} \mathrm{C}$. All chelators were obtained from Molecular Probes.

Loading of astrocytes with calcium indicators and chelators. Loading of the cells was performed at $37^{\circ} \mathrm{C}$. The culture medium was exchanged with experimental solution containing $5 \mu \mathrm{M}$ fluo-3 AM (unless otherwise specified in the text), $0.01 \%$ pluronic, and the desired final concentration of a given calcium buffer. Control cultures were loaded with fluo-3 alone. The final DMSO concentration never exceeded $0.25 \%$, which produced no observable adverse effects on neuronal morphology or calcium wave propagation in controls. The calcium buffer and/or indicators were allowed to accumulate intracellularly for $1.5 \mathrm{hr}$, after which the cultures were rinsed in buffer-free media to remove any remaining extracellular chelators. Astrocytic viability was not affected by any of the chelators, as noted by propidium iodide exclusion and by the ability of the cells to retain the cytoplasmic $\mathrm{Ca}^{2+}$ indicator throughout the experiment.

$\mathrm{Ca}^{2+}$ imaging. The cultures were placed on the stage of an inverted microscope (IMT-2; Olympus, Tokyo, Japan) and viewed through a $20 \times$ lens (Olympus Uapo/340, 20×/0.75; or Olympus ultralong warning distance, $20 \times / 0.40)$. Fluo-3-loaded cultures were studied using a laserscanning confcal microscope equipped with a $25 \mathrm{~mW}$ argon laser (MRC600, Bio-Rad, Hertfordshire, England) using the following parameters: $488 \mathrm{~nm}$ excitation and $515 \mathrm{~nm}$ emission wavelengths, pinhole size set at $7 \mathrm{~mm}$, and laser attenuated to $1 \%$ with neutral density filters. The gain and black level settings were kept constant whenever comparisons were being made between different cultures. $\mathrm{Ca}^{2+}$ images were collected every 1-3 sec and were archived on a Panasonic TQ-2028F for later analysis. Two to five images were recorded before initiating a $\mathrm{Ca}^{2+}$ wave with mechanical stimulation (see below), and recordings continued for $20-30 \mathrm{sec}$ thereafter. Calcium waves were studied in calcium chelatorloaded cultures and in control cultures on the same day and in the same batch of cultures to avoid artifact arising from the use of nonratiometric dyes. In some experiments, the confocal microscope was set to linescanning mode, and fluo-3 fluorescence changes were monitored at 500 scans/sec along a line drawn through an individual astrocyte that a wave propagated. Experiments in fura-2-loaded cultures were similarly executed, except that the cultures were alternately excited with 340 and 380 $\mathrm{nm}$ light, and the $510 \mathrm{~nm}$ bandpass emission of the fura- 2 dye was imaged using a Dage, Inc. SIT68 camera and Image-1/FL software (Universal Imaging Corp., West Chester, PA).

Mechanical stimulation. All experiments were performed at room temperature $\left(21 \pm 2^{\circ} \mathrm{C}\right)$. To initiate a $\mathrm{Ca}^{2+}$ wave, an astrocyte in the center of the viewing field was mechanically stimulated by vertically lowering a glass micropipette (tip diameter, $<1 \mu \mathrm{m}$ ) mounted at a $45^{\circ}$ angle on a micromanipulator, as described by Charles et al. (1991). Physical contact between the micropipette and the astrocyte lasted $<1$ sec and was visually monitored on the imaging apparatus screen (Fig. 1, arrows). Each group consists of a minimum of seven trials (range, 7-47) obtained from a minimum of three cultures.

Photo-bleaching experiments. Cultures loaded with the different chelators (or DMSO alone) as above were additionally incubated with $4 \mu \mathrm{M}$ 5-carboxy-dichlorofluorescein diacetate for $4 \mathrm{~min}$. This compound is a $\mathrm{pH}$ indicator with a $\mathrm{pK}$ of 4.2 and emits a $\mathrm{pH}$-insensitive signal at physiological pH levels, pH 6.5-8.0, (Nedergaard et al., 1990). After 30 min of rinsing, baseline fluorescence $\left(F_{\mathrm{o}}\right)$ was collected at $0.1 \%$ laser intensity $\left(20 \times\right.$ lense). Then, a field of $500 \mu \mathrm{m}^{2}$ was exposed to $4-5 \mathrm{sec}$ of intense laser light with a neutral density filter at 0 (maximum laser poser, $40 \times$ lense). The microscope was returned to the setting used for recording, and one image was collected immediately thereafter $\left(F_{\mathrm{b}}\right)$ and 5 min afterward $\left(F_{\mathrm{r}}\right)$. The percentage recovery $(r \%)$ was calculated using the following expression: $r \%=\left(F_{\mathrm{r}}-F_{\mathrm{b}}\right) /\left(F_{\mathrm{o}}-F_{\mathrm{b}}\right) \times 100$. The rate of recovery during the initial $2 \mathrm{~min}$ of refill was calculated as $r \% / \mathrm{sec}$. Measurements in these experiments were collected every $10 \mathrm{sec}$ during the initial 2 min of refill.

Measurements of calcium wave parameters and statistics. The fractional change in fluo-3 fluorescence $\left(/ \delta F / F_{\mathrm{o}} ;\right.$ Fig. $2 I I$; see Fig. 4$)$ was calculated as $\left(F_{\mathrm{t}}-F_{\mathrm{o}}\right) /\left(F_{\mathrm{o}}-F_{\mathrm{bk}}\right)$, where $F_{\mathrm{t}}$ represents the fluo-3 intensity value at time $t, F_{\mathrm{o}}$ is the initial fluorescence intensity previous to mechanical stimulation, and $F_{\mathrm{bk}}$ is the background fluorescence intensity. The occurrence of a $\mathrm{Ca}^{2+}$ wave was defined as a $50 \%$ increase in signal intensity over baseline $(\Delta F / F)$ that spread from the stimulated cell and propagated for a minimum of $50 \mu \mathrm{m}$ in at least one direction (the astrocytes were usually $<30 \mu \mathrm{m}$ in diameter). The maximal wave radius was taken as the farthest distance traveled by the wave in any direction from the stimulated cell. Wave velocity was obtained by dividing the maximal wave radius minus $50 \mu \mathrm{m}$ by the time taken to reach that maximal distance. Subtracting $50 \mu \mathrm{m}$ from the maximal radius compensated for the effect of mechanical stimulation on $\left[\mathrm{Ca}^{2+}\right]_{i}$ in the initial phase of the wave.

All comparisons between groups (see Figs. 2-6) were performed using a one-way ANOVA, with the Student-Newman-Keuls method for post hoc pairwise multiple comparisons to detect differences between individual group means. All data are reported as the mean \pm SE. Curve fitting was performed by nonlinear regression using the algorithm of Marquardt-Levenberg (present in Sigmaplot 2.0 software; Jandel Scientific, Corte Madera, CA).

Preparation of antibodies against BAPTA. This will be detailed in a separate publication. Briefly, polyclonal anti-BAPTA antibodies were raised by conjugating BAPTA (tetrapotassium salt; Molecular Probes) to keyhole limpet hemocyanin (KLH) by sulfo- $N$-hydroxysuccinimide (NHS) sodium salt-catalyzed 1-ethyl-3-(3-dimethylaminopropyl)carbodiimide hydrochloride (EDC) condensation (Staros et al., 1986). KLH, sulfo-NHS, and EDC were all obtained from Pierce (Rockford, IL). The conjugate was dialyzed against PBS, emulsified in complete (initial injection) or incomplete Freunds adjuvant, and injected subcutaneously into New Zealand White rabbits at multiple sites. Antisera were collected, and the $\operatorname{IgG}$ fraction was enriched by chromatography on protein A-agarose and dialyzed against PBS.

ELISAs. These were used to characterize the anti-BAPTA antibody, to determine its relative affinity to different BAPTA analogs, and to assay quantitatively the relative loading of the different cell-permeant BAPTA analogs into the cultures. The titer and specificity of the anti-BAPTA antibody were determined by coating 96-well ELISA plates overnight with BAPTA-conjugated bovine serum albumin (BSA; $0.1 \mathrm{mg} / \mathrm{ml}$, prepared as above) at $4^{\circ} \mathrm{C}$. After blocking with $3 \%$ BSA in PBS for $2 \mathrm{hr}$, each well was treated for $2 \mathrm{hr}$ with the antibody and washed three times with blocking solution. Secondary antibody (1:2-4000 donkey anti-rabbit IgG; Amersham, Arlington Heights, IL) was then added for $2 \mathrm{hr}$, and the plates were rewashed and subsequently developed using peroxidase substrate (Boehringer, Bagnolet, France). The absorbance of each well was then read at $405 \mathrm{~nm}$ on a multiwell reader (UV Max; Molecular Devices, 

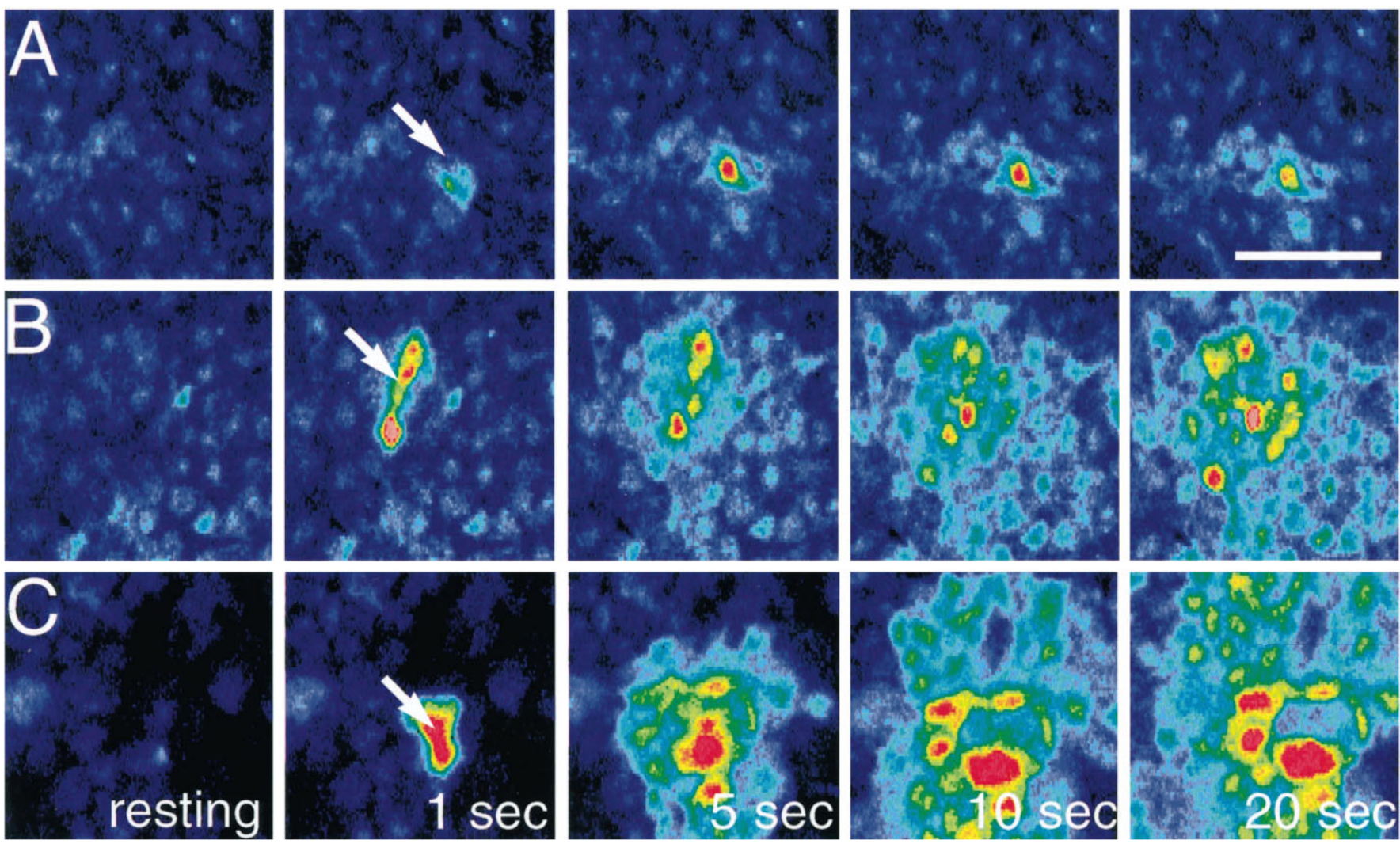

\section{F (pixel value)}
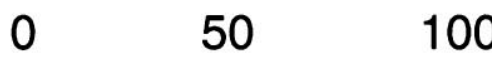

150

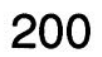

250

Figure 1. Astrocytic calcium waves triggered by mechanical stimulation are attenuated by exogenous calcium buffers having a high but not low $\mathrm{Ca}^{2+}$ affinity. Cultured astrocytes were loaded with fluo-3 (5 $\mu \mathrm{M})$, and mechanical stimulation was applied with a microelectrode tip (see Materials and Methods). $A$, Preincubation of the astrocytes with $30 \mu \mathrm{M}$ BAPTA AM, a permeant high $\mathrm{Ca}^{2+}$ affinity buffer, completely prevents wave propagation. $B$, Similar treatment with $\mathrm{Br}_{2}$-BAPTA AM, a chelator with low $\mathrm{Ca}^{2+}$ affinity, allows wave propagation to occur. $C$, Control cultures. Stimulation produces a radial wave of increasing $\left[\mathrm{Ca}^{2+}\right]_{\mathrm{i}}$ that spreads contiguously among the cells.

Menlo Park, CA) at $22^{\circ} \mathrm{C}$. The titer of the antibody was obtained by serial dilution.

For competition experiments, MAPS-purified anti-BAPTA antibody (1:100) was preincubated for $2 \mathrm{hr}$ with varying concentrations of each of the cell-impermeant (salt) forms of fluo-3 and each of the BAPTA derivatives listed in Table 1 (all from Molecular Probes) before adding to the BSA- and BAPTA-coated ELISA wells.

Determination of the relative loading of different $B A P T A$ analogs into the cells. To compare quanitatively the loading BAPTA to that of its analogs into cells, mixed glial neuronal cultures were prepared as above in 24 well plates and were loaded as described (1.5 hr loading, $30 \mathrm{~min}$ wash) with 5 $\mu \mathrm{M}$ fluo-3 AM alone or in combination with $30 \mu \mathrm{M}$ BAPTA AM, 5,5'-difluoro-BAPTA AM, or 5,5'-dinitro-BAPTA AM. The cultures were then fixed using control medium containing EDC, $20 \mathrm{mg} / \mathrm{ml}$ (Yamamoto and Yasuda, 1979; Tymianski et al., 1997). After blocking overnight with $3 \%$ BSA, each well was washed three times with fresh blocking solution, and then MAPS-purified anti-BAPTA antibody (1: 100 ) was added for $3 \mathrm{hr}$. After further washing, the plate was treated with secondary antibody, developed, and read in the ELISA reader as above.

Immunohistochemistry. Cell cultures were loaded with BAPTA AM as described, washed two times with control solution, and fixed with EDC $\left(40 \mathrm{mg} / \mathrm{ml}\right.$ in control solution) for $1.5 \mathrm{hr}$ at $20^{\circ} \mathrm{C}$. After washing three times with $0.1 \mathrm{M}$ glycine in PBS to quench any unreacted EDC, the cells were permeabilised by washing three times with $0.2 \%$ Triton X-100 in 0.1 $\mathrm{M}$ glycine/PBS. The cells were then blocked overnight at $4^{\circ} \mathrm{C}$ with $10 \%$ heat-inactivated goat serum in PBS. The cultures were then incubated for $12 \mathrm{hr}$ at $4^{\circ} \mathrm{C}$ with polyclonal anti-BAPTA $(1: 200$ dilution in blocker containing $0.2 \%$ Triton X-100) or mouse monoclonal anti-GFAP (Biogenex dropper kit) antibodies. After washing four times in blocker, the cells were treated for $4 \mathrm{hr}$ at $20^{\circ} \mathrm{C}$ with secondary antibodies [FITCconjugated goat anti-mouse (Molecular Probes) diluted 1:400 in blocker or Cy5.5 goat anti-rabbit (Jackson Immunoresearch, West Grove, PA)]. The cells were then washed six times with PBS, followd by three washes with $0.1 \mathrm{M}$ phosphate buffer, $\mathrm{pH} 7.4$, mounted in Slowfade, and coverslipped.

\section{RESULTS}

Experiments were performed in confluent cultured astrocytes loaded with the fluorescent $\mathrm{Ca}^{2+}$ indicator fluo-3 AM (5 $\left.\mu \mathrm{M}\right)$. Calcium waves were elicited by mechanical stimulation as described (see Materials and Methods). A brief membrane deformation with a microelectrode tip triggered a rise in the $\left[\mathrm{Ca}^{2+}\right]_{\mathrm{i}}$ that was initially restricted to the stimulated cell (Fig. 1C). After a delay of a few seconds, adjacent astrocytes also underwent $\left[\mathrm{Ca}^{2+}\right]_{\mathrm{i}}$ increases that were subsequently propagated to nearby cells in the syncytium and often extended beyond the field of view (Fig. $1 C$ ). Most $\mathrm{Ca}^{2+}$ waves propagated in a radial manner and in some cases produced $\mathrm{Ca}^{2+}$ oscillations in peripherally positioned cells (Charles et al., 1991). In some cases, the waves propagated in curvilinear patterns, so that cells located away from the wave initiation site sometimes exhibited a $\left[\mathrm{Ca}^{2+}\right]_{\mathrm{i}}$ rise before some cells positioned next to the site of mechanical stimulation (Finkbeiner, 1992). However, in all cases, the waves spread in a contiguous manner. For the purposes of data analysis, the occurrence 
I

A
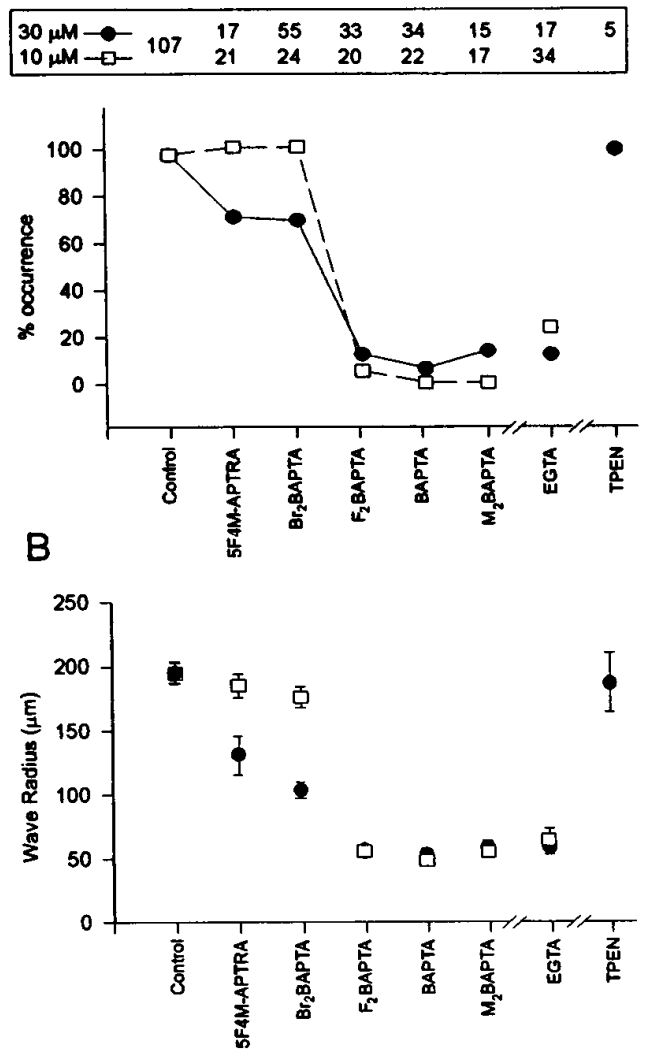

III
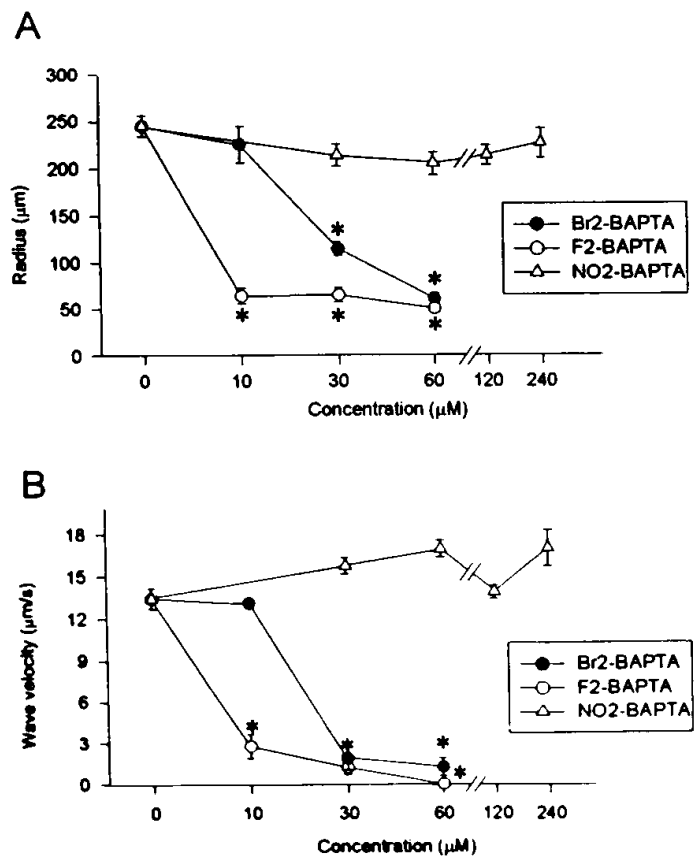

II
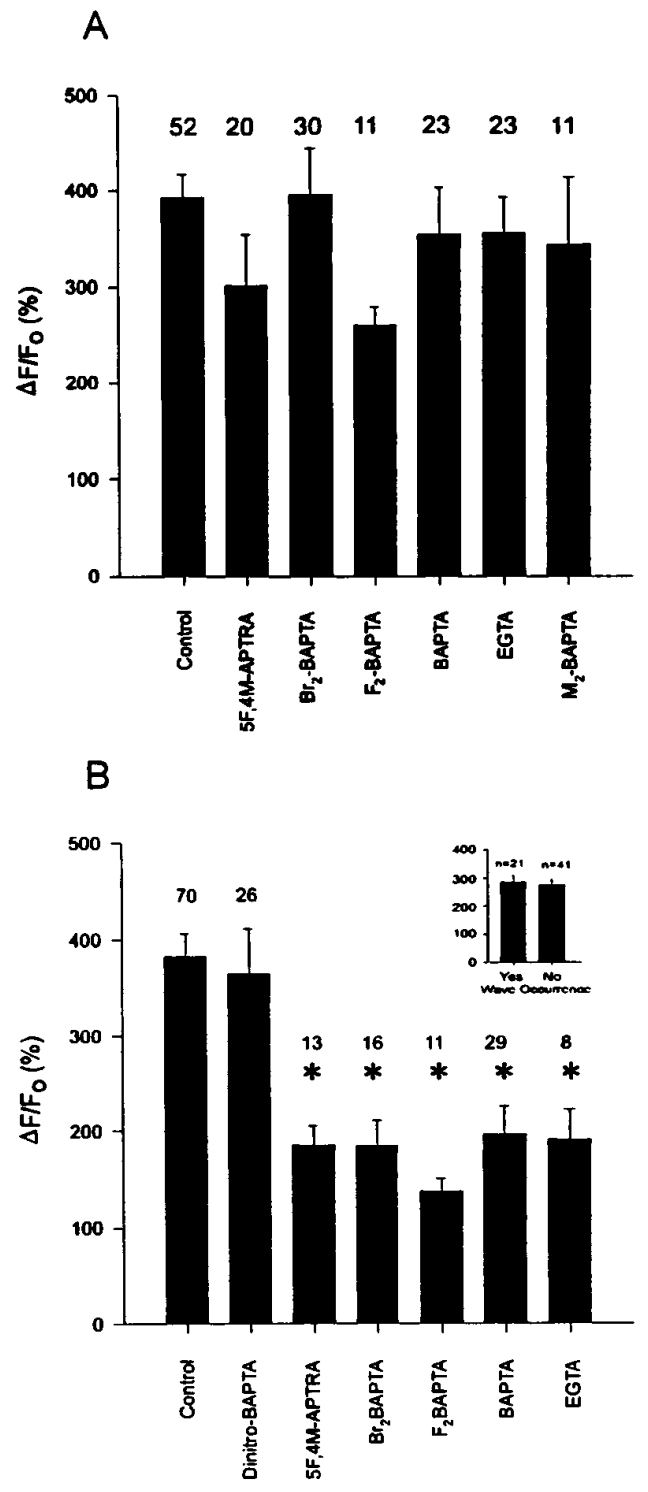

IV

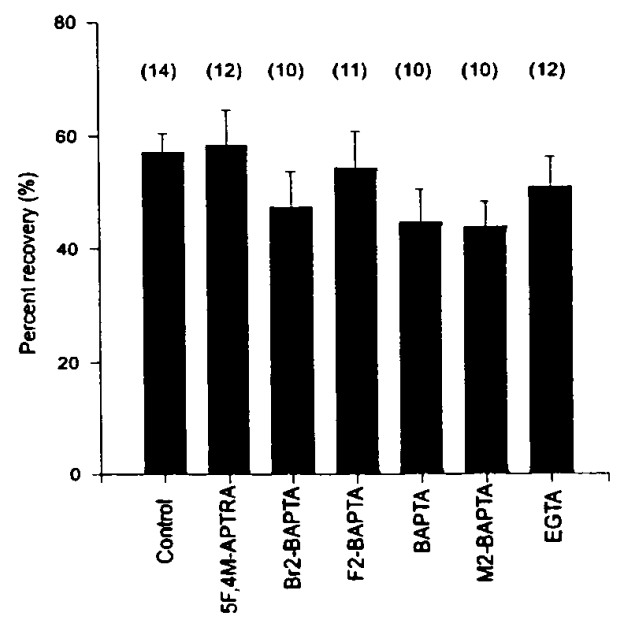




\begin{tabular}{|c|c|c|c|}
\hline Chelator & Abbreviation & $K_{\mathrm{d}}(\mathrm{nM})$ & References \\
\hline $\begin{array}{l}\text { Ethylene glycol bis(b-aminoethyl ether)- } \\
\quad N, N, N^{\prime}, N^{\prime} \text {-tetraacetic acid }\end{array}$ & EGTA & $100-400$ & $\begin{array}{l}\text { Harrison and Bers, } \\
1987\end{array}$ \\
\hline Fura-2 & & 224 & \\
\hline \multicolumn{4}{|l|}{ Grynkiewicz et al., 1985} \\
\hline \multicolumn{4}{|l|}{ Fluo-3 } \\
\hline 5,5'-Dimethyl-BAPTA & $\mathrm{M}_{2}$-BAPTA & $40-150$ & Pethig et al., 1989 \\
\hline $\begin{array}{l}\text { 1,2-Bis(2-aminophenoxy)ethane- } \\
N, N, N^{\prime}, N^{\prime} \text {-tetraacetic acid }\end{array}$ & BAPTA & $100-400$ & Pethig et al., 1989 \\
\hline 5,5'-Difluoro BAPTA & $\mathrm{F}_{2}$-BAPTA & 700 & Pethig et al., 1989 \\
\hline 5,5'-Dibromo BAPTA & $\mathrm{Br}_{2}$-BAPTA & 3,600 & Pethig et al., 1989 \\
\hline $\begin{array}{l}\text { 5-Fluoro-4-methyl-2-aminophenol- } \mathrm{N}, \mathrm{N}, \mathrm{O} \text { - } \\
\text { triacetic acid }\end{array}$ & 5F, 4M-APTRA & 12,000 & \\
\hline 5,5'-Dinitro BAPTA & $\mathrm{N}_{2}$-BAPTA & 20,000 & Pethig et al., 1989 \\
\hline Tetrakis(2-pyridylmethyl)ethylenediamine & TPEN & & \\
\hline
\end{tabular}

of a $\mathrm{Ca}^{2+}$ wave was defined as a $50 \%$ increase in signal intensity over baseline $\left(\Delta F / F_{\mathrm{o}}\right)$ that spread from the stimulated cell and propagated for a minimum of $50 \mu \mathrm{m}$ in at least one direction. The probability of wave initiation was defined as the percentage of waves initiated after mechanical stimulation of the central cell. Wave velocities were defined as propagation per second and calculated by dividing the maximal wave radius minus $50 \mu \mathrm{m}$ by the time taken to reach that maximal distance (see Materials and Methods).

\section{An exogenous $\mathrm{Ca}^{2+}$ chelator blocks astrocytic $\mathrm{Ca}^{2+}$ waves}

Mechanical stimulation reproducibly triggered $\mathrm{Ca}^{2+}$ waves in $>95 \%$ of control cultures loaded with $5 \mu \mathrm{M}$ fluo-3 AM. Figure $1 C$ is representative of one series in which 133 of 140 mechanical stimuli produced waves that propagated with an average velocity of $13.9 \pm 0.8 \mu \mathrm{m} / \mathrm{sec}$ and a radius of $204 \pm 6.7 \mu \mathrm{m}$ (mean $\pm \mathrm{SE})$.

In some experiments the cultures were loaded with, in addition to fluo-3 AM, the cell-permeant $\mathrm{Ca}^{2+}$ chelator BAPTA AM (30 $\mu \mathrm{M})$. Intracellular cleavage of the AM moiety by nonspecific esterases produces the ionized BAPTA molecule that chelates $\mathrm{Ca}^{2+}$ ions with high affinity and specificity (Tsien, 1980, 1981). This completely abolished calcium wave production in all cells examined ( $n=42$ cells). Similarly, all but two astrocytes in cultures loaded with $10 \mu \mathrm{M}$ BAPTA AM also failed to trigger calcium waves (23 of 25 cells). In these cells, the mechanical deformation of the cell membrane caused a rise in $\left[\mathrm{Ca}^{2+}\right]_{i}$ in the stimulated cell that failed to propagate to neighboring astrocytes (Fig. 1A). More forceful mechanical stimulation resulted in lysis of the membrane of the cell but could not trigger a calcium signal in neighboring cells.

\section{$\mathrm{Ca}^{2+}$ affinity of exogenous $\mathrm{Ca}^{2+}$ buffers dictates their effects on wave occurrence}

To further examine the effects of exogenous $\mathrm{Ca}^{2+}$ buffers on astrocytic calcium wave propagation, we used a number of cellpermeant calcium chelators having a range of calcium affinities, chemical structures, and calcium-binding kinetics. If cytoplasmic calcium buffering is an important determinant of calcium wave characteristics, then adding these exogenous chelators to the cytoplasm should alter the calcium waves according to the specific physical properties and intracellular concentrations of the chosen chelator. The strategy of using different exogenous $\mathrm{Ca}^{2+}$ chelators has been used in the past in neurons, but not in glia, to study $\mathrm{Ca}^{2+}$-dependent phenomena such as synaptic transmission, cell membrane excitability, and neurotoxicity (Adler et al., 1991;

$\leftarrow$

Figure 2. I, The occurrence of $\mathrm{Ca}^{2+}$ waves depends on the $\mathrm{Ca}^{2+}$ affinity of the cytoplasmic buffer. Cultures were simultaneously loaded using $5 \mu \mathrm{M}$ fluo-3 AM, and the given chelator and $\mathrm{Ca}^{2+}$ waves were mechanically elicited. Top panel, Total number of experiments performed using $30 \mu \mathrm{M}$ (solid circles) or $10 \mu \mathrm{M}$ (open squares) concentrations of each permeant chelator. $A$, Effects of various buffers on the probability of wave occurrence as defined in Materials and Methods. Note the considerable differences between the ability of $\mathrm{Br}_{2}$-BAPTA AM and $F_{2}$-BAPTA AM to attenuate Ca ${ }^{2+}$ waves. $B$, Effects of each buffer on the $\mathrm{Ca}^{2+}$ wave radius. In the event that no wave was triggered, the radius was taken to be $50 \mu \mathrm{m}$. Note in $A$ and $B$ that EGTA AM, a slow buffer, has effects similar to BAPTA AM, whereas TPEN, a permeant $\mathrm{Zn}^{2+}$ buffer, has no effect. $I I$, The ability of mechanical stimulation to raise $\left[\mathrm{Ca}^{2+}\right]_{\mathrm{i}}$ in the initial cell does not correlate with the probability of wave generation. $A$, Plot of the average value of the fractional increase in fluo-3 fluorescence $\left(\Delta F / F_{\mathrm{o}}\right)$ triggered in the mechanically stimulated astrocyte. At $10 \mu \mathrm{M}$ loading concentrations, none of the chelators appreciably attenuated the rise in $\Delta F / F_{\mathrm{o}}$, although some of the chelators prevented $\mathrm{Ca}^{2+}$ wave occurrence (ANOVA, $F=1.04 ; p=0.403$ ). $B$, In contrast, when applied at $30 \mu \mathrm{M}$, all the chelators (with the exception of dinitro-BAPTA, which has extremely low $\mathrm{Ca}^{2+}$ affinity) attenuated the [Ca $\left.{ }^{2+}\right]_{\mathrm{i}}$ rise irrespective of whether $\mathrm{Ca}^{2+}$ waves were produced (asterisks; ANOVA, $F=8.95 ; p<0.0001$ ). Data shown in $A$ and $B$ are mean $\Delta F / F_{\mathrm{o}}$ values obtained 3 sec after mechanical stimulation from the number of trials indicated above each bar regardless of whether a wavewas roduced. Inset, When grouped according to whether a $\mathrm{Ca}^{2+}$ wave was triggered, there was still no relationship between the magnitude of $\Delta F / F_{\mathrm{o}}$ and the ability to trigger a Ca ${ }^{2+}$ wave. $I I I$, The effects of exogenous buffers on $\mathrm{Ca}^{2+}$ waves depend on buffering capacity. $A, B$, Effects of different concentrations of three permeant chelators on wave radius $(A)$ and velocity $(B)$. Data represent means obtained from at least 7 trials at each concentration (range, 7-47 trials). Note that given sufficient chelator loading, a lower-affinity $\mathrm{Ca}^{2+}$ buffer $\left(\mathrm{Br}_{2}\right.$-BAPTA) can have similar effects to a high-affinity buffer $\left(\mathrm{F}_{2}-\mathrm{BAPTA}\right)$. However, a buffer with almost no Ca ${ }^{2+}$ affinity ( $\mathrm{NO}_{2}$-BAPTA), regardless of loading concentration, has no effect. Asterisks in $A$ and $B$ indicate significant differences compared with controls (ANOVA with post-hoc multiple comparisons). IV, Calcium buffers have no effects on gap junction function. Cultures were loaded with the different chelators and with $4 \mu \mathrm{M}$ 5-carboxy-dichlorofluorescein diacetate, which diffuses freely through patent gap junctions. Fluorescence in astrocytes in the center of the field were then bleached by repeatedly scanning the same area using the confocal laser. Photo-bleach recovery in chelator-loaded cells was no different from that observed in untreated cells (ANOVA, $F=1.20 ; p=0.316$ ). Numbers in parentheses indicate numbers of experiments. 
Tymianski et al., 1993, 1994; Winslow et al., 1994; Zhang et al., 1995; Spigelman et al., 1996).

The cultures were simultaneously loaded with fluo-3 AM (5 $\mu \mathrm{M}$ ) and with another permeant chelator for $1.5 \mathrm{hr}$ (see Materials and Methods). Calcium waves were elicited as before. When applied at $10 \mu \mathrm{M}, \mathrm{M}_{2}$-BAPTA AM $\left(K_{\mathrm{d}}, 40-150 \mathrm{nM}\right)$, BAPTA AM $\left(K_{\mathrm{d}}, 100-400 \mathrm{nM}\right)$, and $\mathrm{F}_{2}$-BAPTA AM $\left(K_{\mathrm{d}}, 700 \mathrm{nM}\right)$, all permeant chelators having a high $\mathrm{Ca}^{2+}$ affinity (Pethig et al., 1989), profoundly decreased the probability of triggering a regenerative $\mathrm{Ca}^{2+}$ wave. In contrast, $\mathrm{Br}_{2}$-BAPTA $\left(K_{\mathrm{d}}, 3600 \mathrm{nM}\right)$ and 5F,4M-APTRA $\left(K_{\mathrm{d}}, 12,000 \mathrm{nM}\right)$, which have considerably lower $\mathrm{Ca}^{2+}$ affinities, had virtually no impact on wave occurrence (Figs. $1 B, 2 I A$ ) (Pethig et al., 1989). Also, no subjective differences were seen between the effects of low-affinity chelators and controls when directly viewing the wave throughout the experiment. When applied at higher concentrations $(30 \mu \mathrm{M})$, the two lowaffinity chelators reduced somwhat the probability of $\mathrm{Ca}^{2+}$ wave occurrence (Fig. 21A). However, there remained a clear difference between the ability of mechanical stimulation to trigger a wave in the presence of chelators with $\mathrm{Ca}^{2+}$ affinities equal to or greater than $F_{2}$-BAPTA compared with those having $\mathrm{Ca}^{2+}$ affinities equal to or less than $\mathrm{Br}_{2}$-BAPTA (Fig. 2IA).

Another way to view the effects of the chelators on calcium wave occurrence is to consider their impact on the wave propagation distance. In instances in which waves could be triggered, the different chelators attenuated the maximal $\mathrm{Ca}^{2+}$ wave radius in a manner that also paralleled their $\mathrm{Ca}^{2+}$ affinity and their extracellular loading concentrations (Fig. 2IB).

An attribute of BAPTA and its analogs is that, in addition to selectively binding $\mathrm{Ca}^{2+}$, they also chelate zinc ions with high affinity (Csermely et al., 1989). To exclude a contribution of zinc chelation to the observed effect on $\mathrm{Ca}^{2+}$ waves, we used TPEN, a permeant, selective $\mathrm{Zn}^{2+}$ chelator with no affinity for $\mathrm{Ca}^{2+}$ ions. This compound had no effects on any $\mathrm{Ca}^{2+}$ wave characteristics (Figs. 2IA,B).

Attributes of $\mathrm{Ca}^{2+}$ buffers other than $\mathrm{Ca}^{2+}$ affinity may influence their physiological effects. For example, the speed with which a chelator binds $\mathrm{Ca}^{2+}$ ions $\left(\mathrm{Ca}^{2+}\right.$ association rate $)$ has previously been shown to affect phenomena such as synaptic transmitter release (Adler et al., 1991; Spigelman et al., 1996) and $\mathrm{Ca}^{2+}$-dependent membrane exitability (Zhang et al., 1995) independently of $\mathrm{Ca}^{2+}$ affinity. For example, BAPTA effectively attenuates the release of synaptic transmitter in many preparations in which EGTA $\left(K_{\mathrm{d}}, 100-400 \mathrm{nM}\right)$ (Harrison and Bers, 1987), a chelator that has a similar $\mathrm{Ca}^{2+}$ affinity to BAPTA but that binds $\mathrm{Ca}^{2+}$ ions 100-400 times more slowly (slow $K_{\text {on }}$ and $K_{\text {off }}$ ), is ineffective (Haraf uji and Ogawa, 1980; Smith et al., 1984; Kao and Tsien, 1988; Adler et al., 1991; Stern, 1992; Winslow et al., 1994; Zhang et al., 1995). To determine whether the effects observed presently on $\mathrm{Ca}^{2+}$ waves were affinity-related, rather than being attributable to the $\mathrm{Ca}^{2+}$ binding kinetics of the buffers, we tested the effects of EGTA on our preparation. This chelator was as effective as BAPTA in attenuating $\mathrm{Ca}^{2+}$ waves (Figs. $2 I A, B$ ), indicating that the wave phenomenon is more likely dependent on the capacity rather than the kinetics of cytoplasmic $\mathrm{Ca}^{2+}$ buffers.

\section{A large initial $\left[\mathrm{Ca}^{2+}\right]_{i}$ signal is insufficient to trigger regenerative waves}

We next examined the dependence of $\mathrm{Ca}^{2+}$ waves on the magnitude of the initiating $\left[\mathrm{Ca}^{2+}\right]_{\mathrm{i}}$ signal. Because some $\mathrm{Ca}^{2+}$ buffers can considerably attenuate stimulus-evoked $\left[\mathrm{Ca}^{2+}\right]_{\mathrm{i}}$ changes $(\mathrm{Ne}-$ her, 1986; Neher and Augustine, 1992; Tymianski et al., 1993, 1994), we used this property to examine whether $\left[\mathrm{Ca}^{2+}\right]_{\mathrm{i}}$ in the stimulated cell will dictate the probability of wave generation. The fractional increases in fluo-3 fluorescence $\left(\Delta F / F_{\mathrm{o}}\right)$ elicited by mechanical stimulation were examined in astrocytes loaded with the different chelators. If the $\mathrm{Ca}^{2+}$ wave depends on the initial $\left[\mathrm{Ca}^{2+}\right]_{\mathrm{i}}$ rise, then $\Delta F / F_{\mathrm{o}}$ should be less in cells in which waves were blocked compared with $\Delta \mathrm{F} / \mathrm{F}_{\mathrm{o}}$ in astrocytes that successfully propagated a wave to neighboring cells. Figure $2 I I A$ shows that at $10 \mu \mathrm{M}$ loading concentrations, none of the chelators significantly altered the measured calcium rise in the stimulated cell (ANOVA, $F=1.04 ; p=0.403$ ), despite the fact that the highaffinity chelators completely blocked wave generation (Fig. 2IA). By contrast, at higher loading concentrations $(30 \mu \mathrm{M})$, the chelators described thus far significantly attenuated the mechanically evoked astrocytic calcium increase compared with controls (Fig. $2 I I B$; ANOVA, $F=8.95 ; p<0.0001)$, irrespective of their capacity to attenuate calcium wave propagation. In addition, analyzing fluo-3 fluorescence changes in stimulated cells in which waves were triggered as compared with cells in which no wave was seen also failed to reveal a difference in the relative $\left[\mathrm{Ca}^{2+}\right]_{\mathrm{i}}$ change (Fig. $2 I I B$, inset; Student's $t_{60}=0.38 ; p=0.702$ ). Thus, raising $\left[\mathrm{Ca}^{2+}\right]_{\mathrm{i}}$ locally with the initial mechanical stimulus did not suffice to trigger a calcium wave when the buffer content of surrounding cells was increased, presumably because the ability of $\left[\mathrm{Ca}^{2+}\right]_{i}$ to rise to adequate levels in neigboring cells was impeded.

At high concentrations, BAPTA-derived $\mathrm{Ca}^{2+}$ chelators can block $\mathrm{IP}_{3}$-induced $\mathrm{Ca}^{2+}$ release from internal stores (Richardson and Taylor, 1993). This pharmacological effect, which is independent of the $\mathrm{Ca}^{2+}$ affinity of the chelator, could account for the $\left[\mathrm{Ca}^{2+}\right]_{\mathrm{i}}$-lowering effects of the chelators seen in Figure $2 I I B$. To control for this possibility, and also for the effects of the AM moiety that may accumulate intracellularly, we examined the effects of the permeant BAPTA analog $\mathrm{NO}_{2}$-BAPTA AM. Because of its extremely low $\mathrm{Ca}^{2+}$ affinity $\left(K_{\mathrm{d}}\right.$ for $\mathrm{Ca}^{2+}, \sim 20 \mathrm{mM}$; Pethig et al., 1989), it would not be expected to chelate $\mathrm{Ca}^{2+}$ ions significantly in the present preparation. This chelator, when applied at $30-240 \mu \mathrm{M}$, had no effect whatsoever on $\left[\mathrm{Ca}^{2+}\right]_{\mathrm{i}}$ (Fig. $2 I I B$ ) or on other wave characteristics (see Fig. 2IIIA,B). Thus, the effects of the other chelators were also unlikely to be attributed to pharmacological mechanisms not specifically associated with $\mathrm{Ca}^{2+}$ binding or to any effects of the AM moiety.

\section{$\mathrm{Ca}^{2+}$ waves are attenuated by the fluorescent indicators used to measure them}

Fluorescent $\mathrm{Ca}^{2+}$ indicators such as fluo-3 and fura- 2 are structurally derived from BAPTA (Grynkiewicz et al., 1985; Minta et al., 1989) and share many of the physical characteristics of their parent molecule, including similar $\mathrm{Ca}^{2+}$ affinity, binding kinetics, and cytoplasmic mobility. Because of the dramatic blocking effects of BAPTA AM on the $\mathrm{Ca}^{2+}$ wave, we examined the possibility that commonly used fluorescent indicators may themselves significantly modify the wave that is being studied. Mechanically triggered calcium waves were produced as described in astrocytes loaded with varying concentrations of the cellpermeant, ratiometric calcium indicator fura-2 AM. This indicator has the advantage over fluo-3 of reporting a measurement that is independent of intracellular dye concentration, which is expected to differ among the test groups.

Loading the cells with increasing concentrations of fura-2 markedly attenuated both the distance of spread (radius; Fig. 3A) 
A

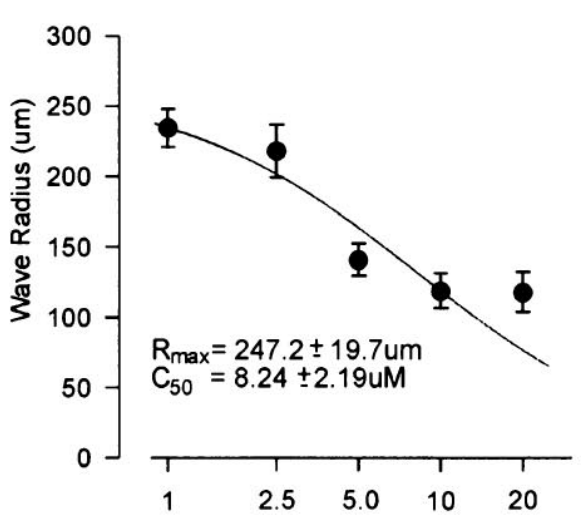

[fura-2] (uM)
B

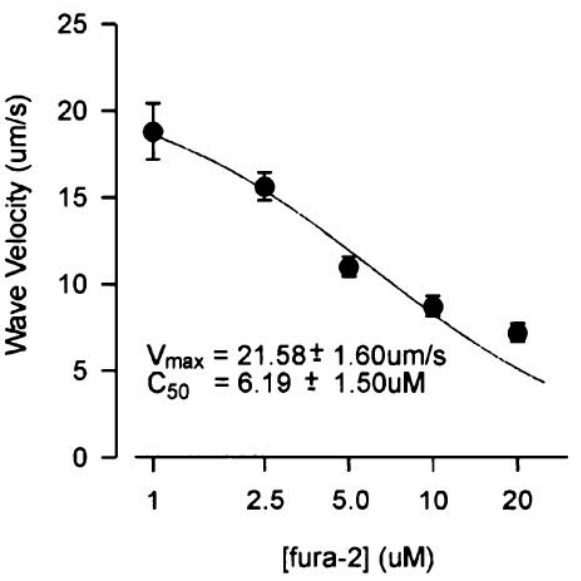

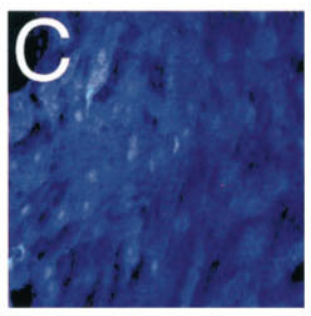
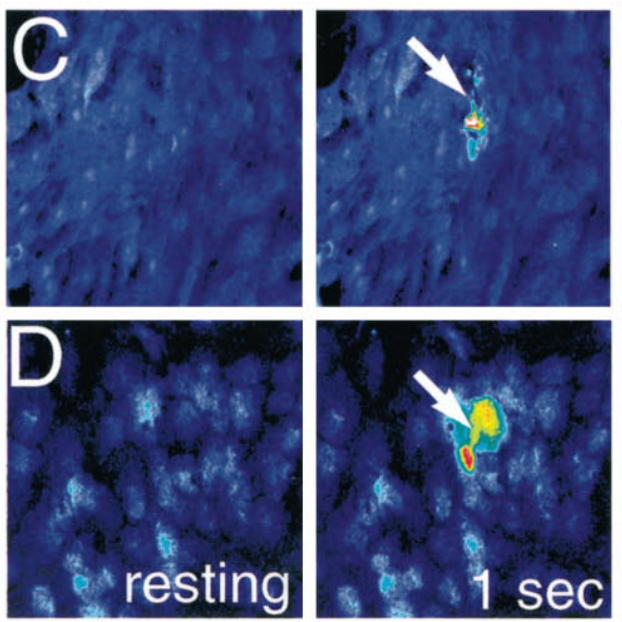
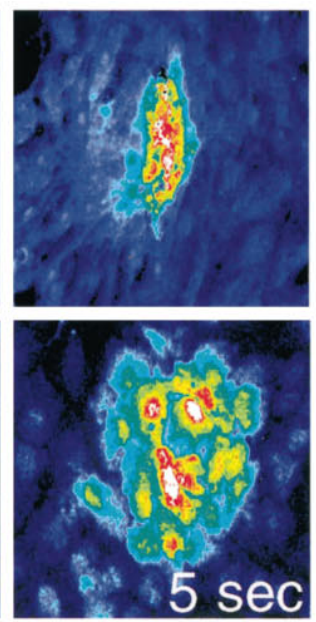
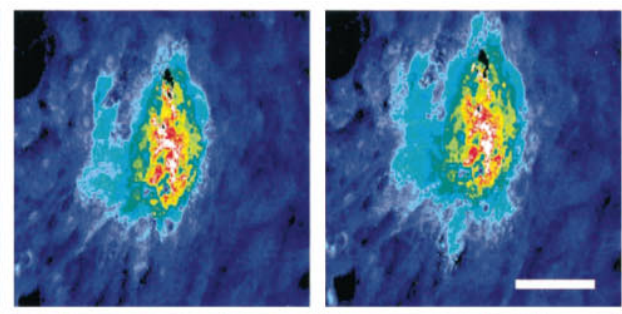

$\mathrm{Ca}^{2+i}(\mathrm{nM})$

1500

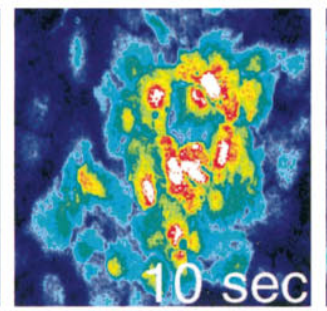

1000

500

100

80

Figure 3. Fura-2, an indicator commonly used to study $\mathrm{Ca}^{2+}$ waves, attenuates them. Cultures were loaded with the indicated concentrations of fura-2 $\mathrm{AM}$, and $\mathrm{Ca}^{2+}$ waves were triggered as described. $A$, Effects of different loading concentrations on wave radius. $B$. Effects on wave propagation velocity. Solid lines in $A$ and $B$ indicate the best fit curves fitted to the equation $E=\left(E_{\max } \times C_{50}\right) /\left(C_{50}+\right.$ [fura] $)$, where $E$ is either wave radius or velocity, and $C_{50}$ is the half-maximally effective concentration. Values of $R_{\max }$ and $V_{\max }$ indicate extrapolations to the situation in which no exogenous buffer is present ([fura] $=0$ ). The effects of fura- 2 in $A$ and $B$ became statistically significant at concentrations of $\geq 5 \mu \mathrm{M}$ (ANOVA, $F=12.9 ; p<0.0001$, followed by pairwise multiple comparisons by the Newman-Keuls method). Data represent means obtained from at least 8 trials at each concentration (range, $8-18$ trials). $C, D$, Time-lapsed fluorescent images showing mechanically induced $\mathrm{Ca}^{2+}$ wave at 20 and $2.5 \mu \mathrm{M}$ loading concentrations of fura-2, respectively. Note the substantial reduction in wave radius in $C$ compared with $D$.

and the velocity of propagation (Fig. $3 B$ ) of the calcium waves. These attenuating effects on wave radius and velocity became statistically significant at fura- 2 AM concentrations of $\geq 5 \mu \mathrm{M}$ [one-way ANOVA, $p<0.0001$ for 5, 10, and $20 \mu \mathrm{M}$ fura-2 AM (Fig. 3C) compared with 1 and $2.5 \mu \mathrm{M}$ (Fig. 3D)]. Extrapolating the data to the situation in which no exogenous buffer was present in the cells (zero fura-2) suggested a maximal wave propagation radius of $247 \pm 20 \mu \mathrm{m}$ and an average velocity of $21 \pm 2 \mu \mathrm{m} / \mathrm{sec}$ (Fig. 3A,B).

These findings demonstrate that both the spatial and temporal characteristics of astrocytic $\mathrm{Ca}^{2+}$ waves can be modulated by maneuvers that modify the apparent calcium-buffering capacity of the cytoplasm. We also noted that although triggering of waves became more difficult at the higher fura-2 AM concentrations (10 and $20 \mu \mathrm{M} ; 3$ failures from 18 mechanical stimulations), this compound alone was not as effective as the nonfluorescent BAPTA analogs at blocking the waves. This suggests that the effects observed with the other compounds were additive to those of the reporter $\mathrm{Ca}^{2+}$ dye that was, by necessity, already present in the cells. Because of this observation, we selected a concentration of 5 $\mu \mathrm{M}$ fluo-3 for the majority of our experiments. This minimal dye concentration produced an acceptable signal-to-noise ratio for $\mathrm{Ca}^{2+}$ imaging and allowed most waves to propagate for $>200 \mu \mathrm{m}$.

\section{$\mathrm{Ca}^{2+}$ buffer attenuation of wave propagation radius and velocity depends on buffering capacity}

$\mathrm{Br}_{2}$-BAPTA and $F_{2}$-BAPTA, buffers having relatively low and high $\mathrm{Ca}^{2+}$ affinities, respectively (Table 1 ), had markedly different effects on $\mathrm{Ca}^{2+}$ wave occurrence (Fig. 2IA). To establish whether these contrasting effects were attributable to diminished buffering capacity when the high $K_{\mathrm{d}}$ chelator was used, we tested a range of concentrations of both chelators, as well as an $\mathrm{NO}_{2}$ BAPTA AM control. If the effects of the chelators on calcium waves are purely dependent on buffering capacity, then increasing the intracellular quantity of a low-affinity chelator should mimic the effects of lower quantities of a chelator with a higher $\mathrm{Ca}^{2+}$ affinity.

As seen in the case of fura-2 (Fig. 3), increasing the loading concentrations of the permeant chelators attenuated wave propagation radius and velocity (Figs. $2 I I I A, B)$. Consistent with a 


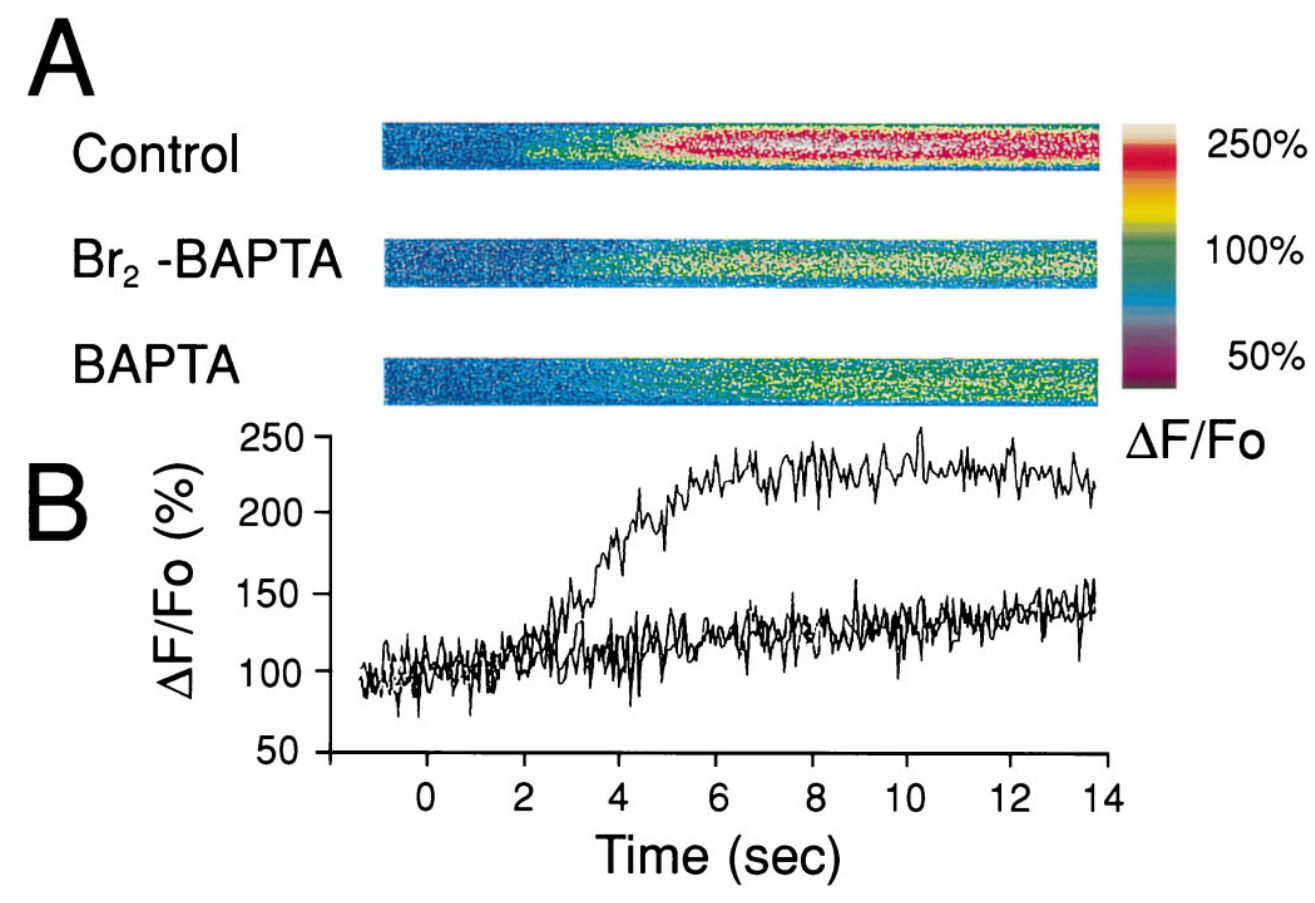

Figure 4. Wave velocity attenuation occurs at the level of the cytoplasm of individual astrocytes. Confocal line scans were obtained from single astrocytes in the path of a sucessfully propagating $\mathrm{Ca}^{2+}$ wave. The cultures were pretreated with the indicated chelators $(30 \mu \mathrm{M}) . A$, Selected line scan images illustrating the differences in the rate and extent of rise of fluo-3 fluorescence in chelator-treated versus untreated astrocytes. $B$, Averaged values of the fractional change in fluo-3 fluorescence $(\Delta F /$ $F_{\mathrm{o}}$ ) over time for each chelator group. Note that both BAPTA and $\mathrm{Br}_{2}$ BAPTA at these concentrations reduce wave velocity to an equal degree (Fig. $5 B$ ), a finding reflected by the equally attenuated rate of change of $\Delta F / F_{\mathrm{o}}$ in the individual wave-carrying cells (slopes of the rise in $\Delta F / F_{\mathrm{o}}$ were $24.08 \pm$ $3.02,3.73 \pm 0.29$, and $3.87 \pm 0.03 \mathrm{sec}^{-1}$ for controls, $\mathrm{Br}_{2}$-BAPTA, and BAPTA, respectively). dependence on calcium-buffering capacity, the differences between the effects of $F_{2}$-BAPTA and $\mathrm{Br}_{2}$-BAPTA were maximal at lower concentrations and could be completely eliminated by increasing the loading concentrations of the buffers.

\section{$\mathrm{Ca}^{2+}$ buffers attenuate $\mathrm{Ca}^{2+}$ waves without affecting gap junction coupling}

The striking effects of exogenous chelators on calcium wave occurrence, spread, and spread velocity could be accounted for by a number of mechanisms. Two important possibilities include an interference with the spread of the wave between adjacent cells and the slowing of the wave spread within the cytoplasm of individual wave-carrying cells. For example, $\mathrm{Ca}^{2+}$ wave propagation is critically dependent on the coupling of adjoining astrocytes by functional gap junctions and is easily blocked by compounds, such as halothane and octanol, that uncouple gap junctions (Nedergaard, 1994; Steinhardt et al., 1994). We sought to determine whether the blocking effects of the $\mathrm{Ca}^{2+}$ buffers could be ascribed to an effect on gap junctions by quantifying fluorescence recovery after photo-bleaching. Cultures loaded with the different chelators (see Materials and Methods) were also incubated with 5-carboxy-dichlorofluorescein diacetate, a fluorescent compound that freely diffuses through gap junctions and that has fluorescence that can be bleached by repeatedly scanning the same area using the confocal laser. Given sufficient time, however, additional fluorescent dye diffuses from adjacent cells into the bleached area, allowing its fluorescence to recover (see Fig. 2IV, Control). This photo-bleach recovery depends on gap junction patency, because when performed in the presence of gap junction uncouplers (e.g., octanol), this maneuver permanently decreases the fluorescence of the test area (data not shown). However, when photo-bleaching was performed in cultures loaded with the different permeant calcium buffers, photobleach recovery was no different from that observed in untreated cells (ANOVA, $F=1.20 ; p=0.316$ ). These compounds are thus unlikely to affect gap junction patency at the concentrations used in the present experiments. Also, the rate of refill was not significantly altered by BAPTA loading. The rate of refill during the initial $2 \mathrm{~min}$ after photo-bleach was $0.24 \pm 0.04$ and $0.28 \pm$ $0.06 \% / \mathrm{sec}$ in BAPTA-treated $(30 \mu \mathrm{M})$ and control-treated cultures, respectively.

\section{$\mathrm{Ca}^{2+}$ wave slowing occurs inside, not between, individual astrocytes}

Like their effects on $\mathrm{Ca}^{2+}$ wave radius, the effects of the chelators on the wave propagation velocity were concentration-dependent, indicating a dependence of the velocity-attenuating effect on calcium-buffering capacity (Fig. 2IIIB). To determine whether the effect of the chelators on wave velocity could be accounted for by observations in individual cells, we used the line-scanning mode of the confocal microscope to measure the rate of change of the $\left[\mathrm{Ca}^{2+}\right]_{\mathrm{i}}$ signal in single astrocytes found in the path of a spreading $\mathrm{Ca}^{2+}$ wave (see Materials and Methods). We compared the effects of BAPTA AM and $\mathrm{Br}_{2}$-BAPTA AM, both applied at 30 $\mu \mathrm{M}$ concentrations, which significantly attenuated wave velocity (Fig. 2IB). The line scans in Figure 4 show that both chelators significantly and similarly decreased the rate of rise of $\left[\mathrm{Ca}^{2+}\right]_{i}$ compared with controls. This reduction exactly parallelled the effects of these chelators on wave velocity (a sixfold decrease in velocity in Fig. $2 I I I B$ and a sixfold decrease in slope of rise of $\Delta F / F_{\mathrm{o}}$ in Fig. 4). Thus, it is likely that the change in $\mathrm{Ca}^{2+}$ wave propagation velocity occurred because of interference of $\mathrm{Ca}^{2+}$ ion diff usion within the cells, rather than between them. The lack of observable difference between the effects of BAPTA AM and $\mathrm{Br}_{2}$-BAPTA AM, despite their different calcium affinities, is consistent with the notion that at these loading concentrations (30 $\mu \mathrm{M})$ a critical buffering capacity was reached.

\section{The loading of permeant $\mathrm{Ca}^{2+}$ chelators into cells can be studied using a novel antibody to BAPTA}

A significant potential criticism of the conclusions drawn thus far is that the intracellular concentrations of each chelator are unknown. It is conceivable that permeant chelators having different chemical structures will load differently into cells. As a consequence, the magnitude of the effects of a given chelator on the various $\mathrm{Ca}^{2+}$ wave parameters might be accounted for entirely by 
its ability to accumulate inside the cells, rather than by its $\mathrm{Ca}^{2+}$ affinity. For example, the greater ability of $F_{2}$-BAPTA AM to attenuate wave occurrence compared with $\mathrm{Br}_{2}$-BAPTA (Fig. $2 I A$ ) could potentially be attributable to a greater accumulation of the former compound into the cells.

To investigate the loading of the chelators into the cells, we raised and characterized polyclonal antibodies to the BAPTA pentapotassium salt (see Materials and Methods) and developed a method to reliably fix intracellular BAPTA in BAPTA AMloaded cultures using the cross-linking agent EDC (Tymianski et al., 1997). Because the cross-linking reaction occurs at the $\mathrm{C}$ terminals of the $\mathrm{Ca}^{2+}$-chelating site of the buffers, the method of EDC fixation distinguishes between de-esterified and non-deesterified chelator, because the latter is not fixed and is removed during processing. Figure 5 shows that intracellular BAPTA can be labeled and studied using this anti-BAPTA antibody and reveals that BAPTA loads into all cells in the cultures, neurons and glia alike. Control experiments (data not shown) included the application of anti-BAPTA antibody to cultures not loaded with BAPTA AM and the application of secondary antibody to loaded cultures in the absence of the primary BAPTA antibody. These revealed that the BAPTA staining is highly selective, and background staining was undetectable (data not shown).

\section{Structurally different cell-permeant $\mathrm{Ca}^{2+}$ chelators load into cells at equivalent final concentrations}

Using the anti-BAPTA antibody, we proceeded to study quantitatively the loading of BAPTA and its analogs into the cultures to determine whether the effects of these chelators on $\mathrm{Ca}^{2+}$ waves could be attributed to a differential loading into cells. First, using ELISAs, competition experiments were performed to determine the affinity of the polyclonal anti-BAPTA antibody for the salts of the different BAPTA analogs used in the present studies. Figure $6 A$ illustrates that the affinity of the antibody varied for the different compounds. It was maximal for BAPTA and decreased progressively as the size of the substituents on the aromatic BAPTA rings increased. The antibody had the least affinity for fluo-3 and, as such, could be used to distinguish the loading of different BAPTA analogs from fluo-3 even when they were loaded simultaneously into cells, as was done in the present studies. The differential affinity of the antibody to the various chelator salts limited its usefulness for detecting $\mathrm{M}_{2}$-BAPTA and $\mathrm{Br}_{2}$-BAPTA, for which its affinity was minimal. However, it could be used to detect BAPTA, $F_{2}$-BAPTA, and $\mathrm{NO}_{2}$-BAPTA if appropriate scaling factors were used to compensate for differences in affinity for the three chelators.

Next, mixed glial-neuronal cultures grown in 24 well plates were loaded with fluo-3 AM $(5 \mu \mathrm{M})$ with or without $30 \mu \mathrm{M}$ BAPTA AM, $F_{2}$-BAPTA AM, or $\mathrm{NO}_{2}$-BAPTA AM using the same loading protocol used in the other experiments in this report (see Materials and Methods). The cultures were then EDC-fixed (20 mg/ml control solution), labeled with the antiBAPTA antibody, and assayed by ELISA as described in Materials and Methods. The antibody labeling of cultures loaded with the different permeant chelators paralleled exactly the affinity of the antibody for the specific chelator salt (Fig. 6B). When adjusted for these affinity differences (Fig. 6C), it was clear that there were no differences in the final intracellular concentrations of the different chelators when these were applied as the permeant esters using the described protocols. Thus, given these data, the observed effects of the different chelators on $\mathrm{Ca}^{2+}$ wave propagation were truly a consequence of their different $\mathrm{Ca}^{2+}$
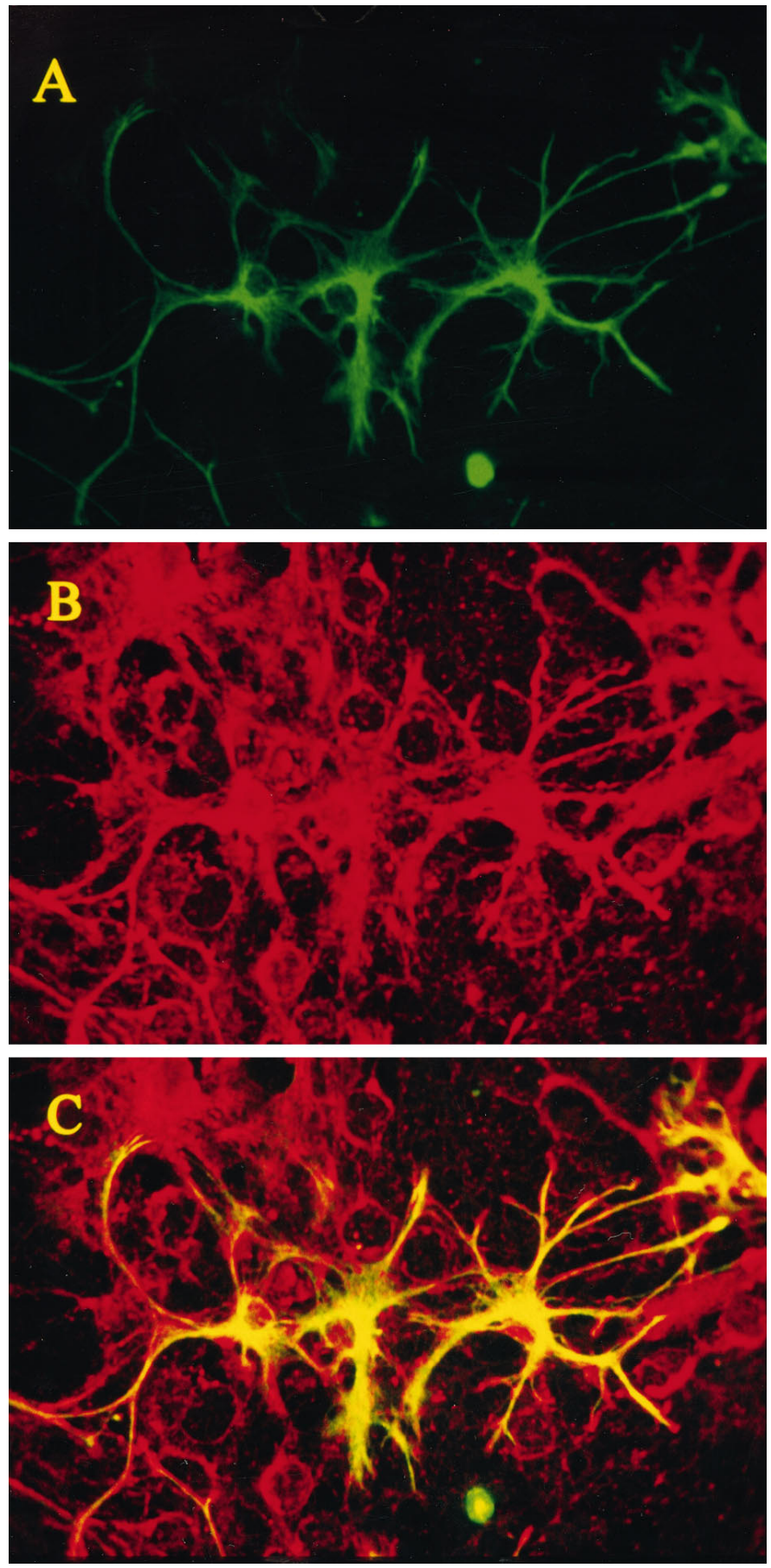

Figure 5. The regional distribution of intracellular BAPTA after loading of BAPTA AM into cultures was detected by an anti-BAPTA polyclonal antibody. Mixed cultures were loaded with BAPTA AM, fixed with EDC as described, and processed for double immunofluorescence staining. Primary antibodies were directed against GFAP and against BAPTA. Secondary antibodies coupled to FITC and Cy5.5, respectively. The specimens were viewed with the MRC-1000 confocal microscope using the $488 \mathrm{~nm}$ (FITC) and $647 \mathrm{~nm}$ (Cy5.5) lines of an Ar/Kr laser. A, GFAP staining confined to the astrocytes in the cultures (FITC-coupled secondary antibody). $B$, BAPTA staining, illustrating the nonselective loading of BAPTA AM into the different cells (including neurons) in the cultures (Cy5.5-coupled secondary antibody). $C$, Merged image of $A$ and $B$, in which ovelapping pixels are shown in yellow. 
Figure 6. When applied onto cultures as the cell-permeant AM esters, different BAPTA analogs accumulate at similar intracellular concentrations as shown by ELISA using the anti-BAPTA antibody. $A$, Competition assays illustrating the relative affinity of the antiBAPTA antibody to the different BAPTA analogs used in the present experiments. MAPS-purified antiBAPTA antibody $(1: 100)$ was preincubated for $2 \mathrm{hr}$ with varying concentrations of each of the BAPTA analog salts listed. The ELISA was then performed as described (see Materials and Methods). $A / A_{\text {max }}$, Normalized absorbance at $405 \mathrm{~nm}$ for each BAPTA analog. Note the high affinity of the anti-BAPTA antibody to BAPTA and $F_{2}$-BAPTA (solid circles and open squares), and the low affinity for fluo-3, $\mathrm{Br}_{2}$-BAPTA, and $\mathrm{M}_{2}$-BAPTA. The antibody has intermediate affinity for DNBAPTA (open circles). B, ELISA performed on cultures after loading with 5 $\mu \mathrm{M}$ fluo-3 AM alone or in comination with $30 \mu \mathrm{M}$ BAPTA AM, $F_{2}$-BAPTA AM, or DN-BAPTA AM (4 cultures per group). $A / A_{\text {fluo-3 }}$, Absorbance normalized to that obtained with fluo-3 alone. Note that the absorbance ratios obtained differ according to the differences in affinity of the anti-BAPTA antibody for the different analogs (as shown in $A$ ). $C$, Data from $B$ scaled according to differences in affinity of the anti-BAPTA antibody, showing that BAPTA, $F_{2}$-BAPTA, and DN-BAPTA all load into the cells at similar concentrations. Scaling factors were defined as $A_{\text {fluo-3 }} /\left(A_{\text {fluo-3 }}-A_{\text {chelator }}\right)$ using values from the competition assays in $A$. The factors were thus derived from the data for 0.1 and $1 \mathrm{~mm}$ chelator and then averaged. $A_{\text {fluo-3 }}$, Normalized fluo-3 absorbance; $A_{\text {chelator }}$, normalized absorbance of the chosen chelator.
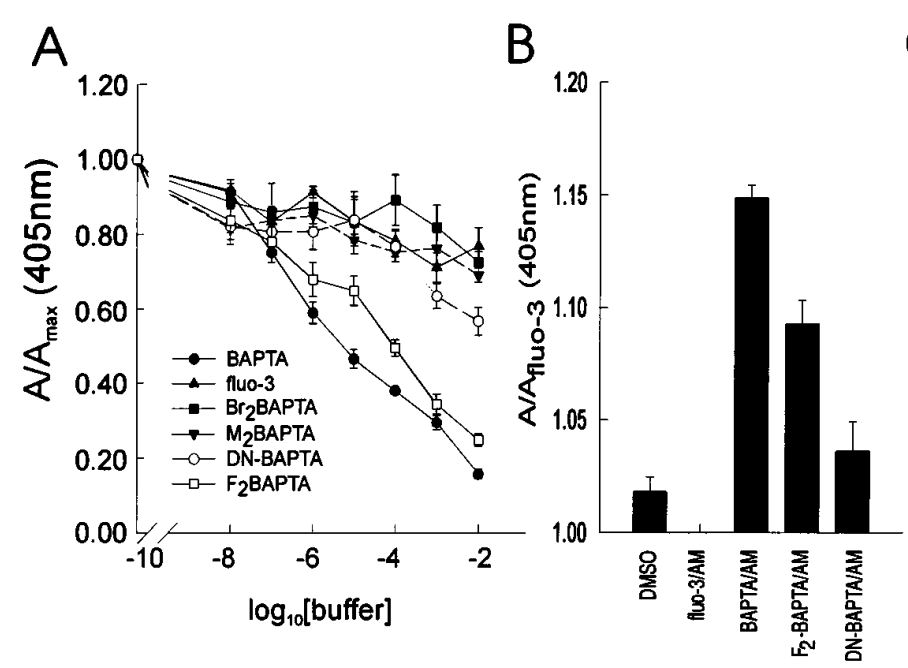

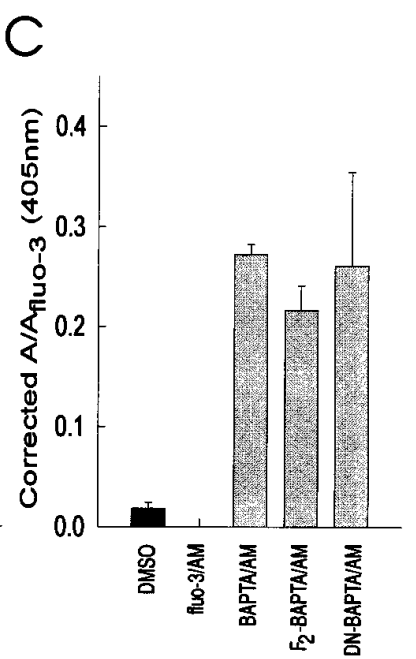

affinities and not attributable to variations in intracellular accumulation.

The use of the anti-BAPTA antibody did not allow quantification of intracellular accumulation of chelators. However, a recent study in neuroblastoma cells estimated the accumulation of intracellular BAPTA and its analogs to be 20 - to 40 -fold of loading concentration of their AM counterparts (at $23^{\circ} \mathrm{C}$; Wang and Thompson, 1995). It is reasonable to assume, therefore, that the intracellular accumulation of the buffers would exceed $200 \mu \mathrm{M}$ when the $10 \mu \mathrm{M}$ AM form is used. At this intracellular concentration, products of metabolism of these chelators, such as ester and formaldehyde, would not produce significant pharmacological effects (see Tsien, 1981).

\section{Endogenous astrocytic calcium buffering behaves like a low $\mathrm{Ca}^{2+}$ affinity buffer}

In the context of the data presented, the observation that the astrocytic waves always terminate spontaneously and seldom travel further than a few hundred micrometers suggests that endogenous buffers may play a role in limiting the spread of the wave. The profound effects of different chelators on calcium waves can be used to infer some of the properties of the endog- enous buffers in astrocytes. The experiments in Figure $3 A$ illustrate that the wave propagation radius can be used as a relative measure of the quantity of exogenous chelator in the cell when a single buffer (fura-2) is used. These data can be extrapolated to the situation in which no exogenous buffer is present, yielding a maximum potential wave radius of $247 \pm 19.7 \mu \mathrm{m}$ under the current experimental conditions. If the hypothesis that calcium waves terminate spontaneously because of the effects of endogenous $\mathrm{Ca}^{2+}$ buffering is correct, then this maximal radius might yield a relative measure of endogenous buffer characteristics; in the situation in which the cultures are loaded with high extracellular concentrations of permeant chelators having different $\mathrm{Ca}^{2+}$ affinities $\left(K_{\mathrm{d}}\right.$ values), there exists a tight logarithmic relationship between the buffer $K_{\mathrm{d}}$ and the wave propagation radius $(r=0.87$; $p<0.0001)$. Because at high concentrations, exogenous calcium chelators outcompete endogenous buffers and dominate $\mathrm{Ca}^{2+}$ dynamics in the cell (Neher and Augustine, 1992; Zhou and Neher, 1993; Neher, 1995), loading the cells with each different buffer alters the effective $K_{\mathrm{d}}$ for $\mathrm{Ca}^{2+}$ of the cytoplasm. The wave radius therefore becomes a relative measure of the $K_{\mathrm{d}}$ for $\mathrm{Ca}^{2+}$ of the cytoplasm. Assuming that in the absence of exogenous 
chelator the wave radius travels at least $200-220 \mu \mathrm{m}$, then the effective $K_{\mathrm{d}}$ for $\mathrm{Ca}^{2+}$ of the endogenous buffers must exceed that of 5F,4M-APTRA and likely exceeds $20 \mu \mathrm{M}$. Thus, if endogenous $\mathrm{Ca}^{2+}$ buffers exist in astrocytic cytoplasm, their behavior is that of a buffer having a relatively low affinity for $\mathrm{Ca}^{2+}$, a property that permits wave propagation and still restricts this mode of intercellular $\mathrm{Ca}^{2+}$ signaling to a very localized range.

\section{DISCUSSION}

Here we have studied directly, for the first time, the effects of cytoplasmic $\mathrm{Ca}^{2+}$ buffering on the propagation of calcium waves in astrocytes. When triggered by mechanical stimulation (Charles et al., 1991), the waves traveled at a constant velocity of $\sim 13-15$ $\mu \mathrm{m} / \mathrm{sec}$, propagated radially for distances of $200-250 \mu \mathrm{m}$, and always terminated spontaneously (Fig. 1C). However, pretreatment with a cell-permeant $\mathrm{Ca}^{2+}$ chelator such as BAPTA dramatically blocked the calcium wave in virtually every case (Fig. $1 A)$. This blocking effect was a consequence of the high $\mathrm{Ca}^{2+}$ affinity of BAPTA, because intermediate effects could be seen with other chelators having lesser $\mathrm{Ca}^{2+}$ affinities (Fig. 2I), and chelators having very low $\mathrm{Ca}^{2+}$ affinities had no effect (Fig. 2III). The blocking effects of the chelators were independent of $\mathrm{Ca}^{2+}$ binding kinetics or of chelation of other ions such as $\mathrm{Zn}^{2+}$ (Fig. $2 I$ ). These effects involved the block of wave propagation, not initiation, because large increases in $\left[\mathrm{Ca}^{2+}\right]_{\mathrm{i}}$ in the mechanically stimulated cell were insufficient to trigger the $\mathrm{Ca}^{2+}$ wave (Fig. $2 I I)$. Wave attenuation was a function of cytoplasmic $\mathrm{Ca}^{2+}$. buffering capacity, because applying increasing concentrations of low $\mathrm{Ca}^{2+}$ affinity buffers mimicked the effects of lesser quantities of high-affinity chelators (Fig. 2III). The effects of the exogenous chelators on $\mathrm{Ca}^{2+}$ wave propagation occurred without affecting gap junction function (Fig. $2 I \mathrm{~V}$ ) and could be completely accounted for by the slowing of $\mathrm{Ca}^{2+}$ ion diffusion within the cytoplasm of individual astrocytes (Fig. 4). The dependence of $\mathrm{Ca}^{2+}$ waves on the quantity and affinity of the cytoplasmic $\mathrm{Ca}^{2+}$ buffer was validated using a novel antibody to BAPTA (Fig. 5), showing that permeant chelators with different structures, when applied at the same concentrations, accumulate to the same degree inside the cells (Fig. 6). The data obtained suggest that endogenous cytoplasmic $\mathrm{Ca}^{2+}$ buffers may be a potent mechanism by which the spread of astrocytic $\mathrm{Ca}^{2+}$ signals can be modulated.

\section{Model of intercellular $\mathrm{Ca}^{2+}$ wave initiation and propagation}

It has been proposed that production of $\mathrm{IP}_{3}$ in the stimulated cell and its subsequent intracellular and intercellular diffusion through gap junctions is responsible for the initiation and propagation of intercellular $\mathrm{Ca}^{2+}$ waves (Rooney and Thomas, 1993; Sanderson et al., 1994). The generated $\mathrm{IP}_{3}$ induces the wave by diff using throughout the cell syncytium, priming $\mathrm{IP}_{3}$ receptors and releasing intracellular $\mathrm{Ca}^{2+}$ from the endoplasmic reticulum (Enkvist and McCarthy, 1992; Finkbeiner, 1992; Berridge, 1993; Charles et al., 1993; Nedergaard, 1994; Venance et al., 1995). The passive diff usion of $\mathrm{IP}_{3}$ (Sneyd et al., 1995) constitutes a primer wave that needs to be relegated to and regenerated by the ensuing $\mathrm{Ca}^{2+}$ induced $\mathrm{Ca}^{2+}$ release in individual cells for its full expression (Jaffe, 1993).

The diffusion of $\mathrm{Ca}^{2+}$ to neighboring $\mathrm{IP}_{3}$ receptors presumably leads to the activation of increasing numbers of $\mathrm{IP}_{3}$-primed $\mathrm{IP}_{3}$ receptors (Parker and Yao, 1991; Yao et al., 1995). Because $\mathrm{Ca}^{2+}$ ions are predominantly buffered by endogenous buffers
(Neher and Augustine, 1992) and diffuse locally on release (Allbritton et al., 1992), their diff usion constitutes another important factor as a rate-limiting step during the initiation and propagation of intercellular $\mathrm{Ca}^{2+}$ wave (Jaffe, 1983; Backx et al., 1989; Lechleiter et al., 1991; DeLisle and Welsh, 1992; Wang and Thompson, 1995).

Therefore, given the above model of intercellular $\mathrm{Ca}^{2+}$ wave initiation and propagation, the impact of exogenous $\mathrm{Ca}^{2+}$ buffers on the properties of $\mathrm{Ca}^{2+}$ waves would derive both from their effects on $\mathrm{Ca}^{2+}$ release and on $\mathrm{Ca}^{2+}$ diffusion.

\section{Mobile exogenous $\mathrm{Ca}^{2+}$ buffers and their potential effects on $\mathrm{Ca}^{2+}$ wave initiation}

In Xenopus oocytes, $\mathrm{Ca}^{2+}$ release through $\mathrm{IP}_{3}$ receptors occurrs on a increasing scale as pacemaker signals, all- or nonpuffs, and propagating $\mathrm{Ca}^{2+}$ waves (Parker and Yao, 1996). The pacemaker signal appears to result from the opening of a single $\mathrm{IP}_{3}$ receptor channel, whereas $\mathrm{Ca}^{2+}$ puffs arise from a concerted opening of clustered $\mathrm{IP}_{3}$ receptor channels that require a local regenerative feedback by cytosolic $\mathrm{Ca}^{2+}$ ions (Yao et al., 1995). A local $\mathrm{Ca}^{2+}$ puff seems to be the minimum functional unit for the $\mathrm{Ca}^{2+}$. induced $\mathrm{Ca}^{2+}$ release through $\mathrm{IP}_{3}$ receptor channels, with cytosolic free $\mathrm{Ca}^{2+}$ concentration peaking at $\sim 100-200 \mathrm{~nm}$ during puffs (2-5 $\mu \mathrm{M}$ during waves).

One major consequence of the presence of an exogenous mobile $\mathrm{Ca}^{2+}$ buffer might be to reduce the peak free $\mathrm{Ca}^{2+}$ concentration at the puff site, thereby attenuating the regenerative potential of the wave. This occurs most effectively in the case of $\mathrm{Ca}^{2+}$ buffers having a rapid forward $\mathrm{Ca}^{2+}$ binding rate (Nowycky and Pinter, 1993). This rate is rapid and similar among BAPTA and its different analogs (Pethig et al., 1989; Pozzan and Tsien, 1989) but is much lower for EGTA (Tsien, 1980; Neher, 1986). Nevertheless, given the relatively slow rise time of $\mathrm{Ca}^{2+}$ puffs (50 msec; Yao et al., 1995), both BAPTA and EGTA are sufficiently fast to reach equilibrium with the $\mathrm{Ca}^{2+}$ ions released for wave initiation, as typical time constants for reaching the $\mathrm{Ca}^{2+} /$ buffer equilibrium are 70 and $0.2 \mu \mathrm{sec}$ for EGTA and BAPTA, respectively (Augustine et al., 1985; Adler et al., 1991). Therefore, given the similarities between the effectiveness of BAPTA and EGTA in blocking wave occurrence (Fig. 2IA), $\mathrm{Ca}^{2+}$ binding rates are unlikely to be important in governing the effects of chelators used in this study.

Conversely, the $K_{\mathrm{d}}$ for the chelators was a significant determinant of their effects on $\mathrm{Ca}^{2+}$ waves (Fig. 2). Because the highaffinity compounds $\mathrm{M}_{2}$-BATPA, $F_{2}$-BAPTA, BAPTA, and EGTA (all with $K_{\mathrm{d}}$ of $<700 \mathrm{nM}$ in vitro) all inhibited wave occurrence, the $\mathrm{Ca}^{2+}$ threshold for the initiation of intercellular $\mathrm{Ca}^{2+}$ wave seems to be in the range of hundreds of nanomolars, a figure consistent on a magnitude scale with other estimates for the magnitude of the initiating $\mathrm{Ca}^{2+}$ puff (Yao et al., 1995; see Iino and Endo, 1992). Furthermore under this model, BAPTA derivatives with a $K_{\mathrm{d}}$ for $\mathrm{Ca}^{2+} \sim 3.6 \mu \mathrm{M}$ (e.g., dibromo-BAPTA), which might be effective in reducing the peak free $\mathrm{Ca}^{2+}$ during the propagating wave (Fig. $2 I I B$ ), will be ineffective in suppressing wave occurrence even at higher loading concentration (Fig. $2 I A)$. This might account for the ability of lower $\mathrm{Ca}^{2+}$ affinity compounds to only partially attenuate $\mathrm{Ca}^{2+}$ wave propagation.

\section{Exogenous mobile $\mathrm{Ca}^{2+}$ buffers and their effects on $\mathrm{Ca}^{2+}$ diffusion}

Exogenous mobile $\mathrm{Ca}^{2+}$ buffers not only affect peak $\left[\mathrm{Ca}^{2+}\right]_{\mathrm{i}}$ values at $\mathrm{Ca}^{2+}$ release sites but also influence the diffusion of 
$\mathrm{Ca}^{2+}$ ions from their source (Neher and Augustine, 1992; Wagner and Keizer, 1994; Wang and Thompson, 1995). Here we found that the intercellular wave velocity is attenuated by highaffinity $\mathrm{Ca}^{2+}$ chelators proportionally to the slowing of the waveevoked rise in $\left[\mathrm{Ca}^{2+}\right]_{i}$ within individual cells (compare $\mathrm{Br}_{2}-$ BAPTA effects in Figs. $2 I I I B$ and 4). This strongly suggests a role for local (intracellular) $\mathrm{Ca}^{2+}$ diffusion in determining the temporal characteristics of intercellular $\mathrm{Ca}^{2+}$ waves. Because calcium chelators slow the diffusion of $\mathrm{Ca}^{2+}$ ions (Augustine and Neher, 1992; Wagner and Keizer, 1994; Neher, 1995), their overall effect, not surprisingly, is to slow or inhibit $\mathrm{Ca}^{2+}$ wave propagation (Jafri and Keizer, 1995).

In view of all these effects, we suggest that high-affinity exogenous $\mathrm{Ca}^{2+}$ chelators block the wave propagation, mostly likely via their inhibition of $\mathrm{Ca}^{2+}$ diff usion with increasing buffering capacity, a factor that is inversely related to the effective diffusion coefficient for the $\mathrm{Ca}^{2+}$ ion under present experimental conditions. Another reason for their inhibition of $\mathrm{Ca}^{2+}$ diff usion and wave activity could be a buffered $\mathrm{Ca}^{2+}$ gradient resulting from a slowed and reduced $\mathrm{Ca}^{2+}$ release in participating cells (see above, Fig. 4), although we have shown it is not necessary for the initiation of intercellular $\mathrm{Ca}^{2+}$ wave.

Like their nonfluorescent couterparts, $\mathrm{Ca}^{2+}$ indicators such as fura-2 and fluo-3 are BAPTA derivatives (Grynkiewicz et al., 1985; Minta et al., 1989), which compound endogenous $\mathrm{Ca}^{2+}$ buffering and may significantly alter intracellular $\mathrm{Ca}^{2+}$ dynamics (Neher and Augustine, 1992; Regehr and Tank, 1992). Here we have shown that a high concentration of fura- 2 indeed can attenuate both the distance of spread and velocity of propagation of astrocytic $\mathrm{Ca}^{2+}$ waves (Fig. 3).

\section{Upregulation of endogenous $\mathrm{Ca}^{2+}$ buffering under pathological conditions}

Endogenous buffering proteins such as calbindin-D28K and its glucose-related forms have been shown to be distributed in both neurons (Kohr et al., 1991) and astrocytes (Bastianelli and Pochet, 1995). Increased expression of mRNA encoding these proteins was detected after acute kainic acid-induced seizure, global ischemia, and brain trauma (Loewenstain et al., 1994) and also in genetically epilepsy-prone rats (Montiel et al., 1994). These imply that potential mechanisms of the $\mathrm{Ca}^{2+}$ regulation under pathological conditions include an upregulation of endogenous buffering capacity in astrocytes. From our study, one possible consequence from such a reactive transformation might be a reduced spread of intercellular $\mathrm{Ca}^{2+}$ waves in the astrocytic networks that might lead to $\mathrm{Ca}^{2+}$ deregulation in surrounding nervous tissue.

In conclusion, we have defined an important feature of glial $\mathrm{Ca}^{2+}$ signaling, i.e., buffer modulation of intercellular $\mathrm{Ca}^{2+}$ waves, with a novel approach using a series of cell-permeant, mobile $\mathrm{Ca}^{2+}$ chelators that bear a range of $\mathrm{Ca}^{2+}$ affinities and could be loaded unequivocally into the cultured cells. The spatial and temporal characteristics of intercellular $\mathrm{Ca}^{2+}$ waves appear to be dictated in part by the total $\mathrm{Ca}^{2+}$ buffer capacity within the astrocytes, including that from the loaded exogenous $\mathrm{Ca}^{2+}$ chelators. With an apparently low endogenous $\mathrm{Ca}^{2+}$ buffer capacity $\left(K_{\mathrm{d}}, \sim 20 \mu \mathrm{M}\right)$ and functional gap junction coupling of astrocytes, the cells are well suited to implement and coordinate their custodial or information-processing functions via the intercellular $\mathrm{Ca}^{2+}$ waves, and could be involved in numerous CNS disorders such as ischemia, trauma, and epilepsy.

\section{REFERENCES}

Adler EM, Augustine GJ, Duffy SN, Charlton MP (1991) Alien intracellular calcium chelators attenuate neurotransmitter release at the squid giant synapse. J Neurosci 11:1496-1507.

Allbritton NL, Meyer T, Stryer L (1992) Range of messenger action of calcium ion and inositol 1,4,5-triphosphate. Science 258:1812-1815.

Augustine GJ, Neher E (1992) Calcium requirements for secretion in bovine chromaffin cells. J Physiol (Lond) 450:247-271.

Augustine GJ, Charlton MP, Smith SJ (1985) Calcium entry during neurotransmitter release at voltage-clamped nerve terminals of squid axons. J Physiol (Lond) 369:163-181.

Backx PH, de Tombe PP, Van Deen JHK, Mulder BJM, ter Keurs HEDJ (1989) A model of propagating calcium-induced calcium release mediated by calcium diffusion. J Gen Physiol 93:963-977.

Bastianelli E, Pochet R (1995) Calbindin-D28K, calretinin, and s-100 immunoreactivity in rat pineal gland during postnatal development. J Pineal Res 18:127-134.

Berridge MJ (1993) Inositol triphosphate and calcium signaling. Nature 361:315-325.

Charles AC, Merrill JE, Dirksen ER, Sanderson MJ (1991) Intercellular signaling in glial cells: calcium waves and oscillations in response to mechanical stimulation and glutamate. Neuron 6:983-992.

Charles AC, Dirksen ER, Merrill JE, Sanderson MJ (1993) Mechanisms of intercellular calcium signaling in glial cells studied with dantrolene and thapsigargin. Glia 7:134-145.

Cornell-Bell AH, Finkbeiner SM, Cooper MS, Smith SJ (1990) Glutamate induces calcium waves in cultured astrocytes: long range glial signaling. Science 247:470-473.

Csermely P, Sandor P, Radics L, Somogyi J (1989) Zinc forms complexes with higher kinetical stability than calcium, 5-F-BAPTA as a good example. Biochem Biophys Res Commun 165:838-844.

Dani JW, Chernjavsky A, Smith SJ (1992) Neuronal activity triggers calcium waves in hippocampal astrocytic networks. Neuron 8:429-440.

DeLisle S, Welsh MJ (1992) Inositol triphosphate is required for the propagation of calcium waves in Xenopus oocytes. J Biol Chem 267:7963-7966.

Enkvist MOK, McCarthy KD (1992) Activation of protein kinase C blocks astroglial gap junction communication and inhibits the spread of calcium waves. J Neurochem 59:519-526.

Finkbeiner S (1992) Calcium waves in astrocytes-filling in the gaps. Neuron 8:1101-1108.

Grynkiewicz G, Poenie M, Tsien RY (1985) A new generation of calcium indicators with greatly improved fluorescence properties. J Biol Chem 260:3440-3450.

Harafuji H, Ogawa Y (1980) Re-examination of the apparent binding constant of ethylene glycol $\operatorname{bis}(\beta$-aminoethyl ether $) N, N, N^{\prime}, N^{\prime}$ tetraacetic acid with calcium around neutral $\mathrm{pH}$. J Biochem 87:1305-1312.

Harrison SM, Bers DM (1987) The effect of temperature and ionic strength on the apparent Ca-affinity of EGTA and the analogous $\mathrm{Ca}^{2+}$-chelators BAPTA and dibromo BAPTA. Biochim Biophys Acta 925:133-143.

Iino M, Endo M (1992) Calcium-dependent immediate feedback control of inositol 1,4,5-triphosphate-induced $\mathrm{Ca}^{2+}$ release. Nature 360:76-78.

Jaffe LF (1993) Classes and mechanisms of calcium waves. Cell Calcium 14:736-745.

Jafri MS, Keizer J (1995) On the roles of $\mathrm{Ca}^{2+}$ diffusion, $\mathrm{Ca}^{2+}$ buffers, and the endoplasmic reticulum in $\mathrm{IP}_{3}$-induced $\mathrm{Ca}^{2+}$ waves. Biophys J 69:2139-2153.

Kao JPY, Tsien RY (1988) $\mathrm{Ca}^{2+}$ binding kinetics of fura-2 and azo-1 from temperature-jump relaxation measurements. Biophys J 53:635-639.

Kohr G, Lambert CE, Mody I (1991) Calbindin-D28K (CaBP) levels and calcium currents in acutely dissociated epileptic neurons. Exp Brain Res 85:543-551.

Kriegler S, Chiu SY (1993) Calcium signaling of glial cells along mammalian axons. J Neurosci 13:4229-4245.

Lechleiter J, Girard S, Peralta E, Clapham D (1991) Spiral calcium wave popagation and annihilation in Xenopus laevis oocytes. Science 252:123-126.

Lowenstein DH, Gwinn RD, Seren MS, Simon RP, McIntosh TK (1994) Increase expression of mRNA encoding calbindin-D28K, the glucoserelated, or the $72 \mathrm{kDa}$ heat-shock protein in the models of acute CNS injury. Brain Res Mol Brain Res 122:299-308.

Meyer T (1991) Cell signaling by second messenger waves. Cell 64:675-678. 
Minta A, Kao JPY, Tsien RY (1989) Fluorescent indicators for cytosolic calcium based on rhodamine and fluorescein chromophores. J Biol Chem 264:8171-8178.

Montiel P, Winsky L, Daly JW, Jobe K, Jacobowitz DM (1994) Alteration in levels of expression of brain calbindin-D28K and calretinin mRNA in genetically prone rats. Epilepsia 36:911-921.

Murphy TH, Blatter LA, Wier WG, Baraban JM (1993) Rapid communication between neurons and astrocytes in primary cortical cultures. J Neurosci 13:2672-2679.

Nedergaard M (1994) Direct signaling from astrocytes to neurons in cultures of mammalian brain cells. Science 263:1768-1771.

Nedergaard M, Desai S, Pulsinelli W (1990) Dicarboxy-dichlorofluorescein: a new fluorescent probe for measuring acidic intracellular $\mathrm{pH}$. Anal Biochem 187:109-114.

Nedergaard M, Goldman S, Desai S, Pulsinelli WA (1991) Acid-induced death in neuron and glia. J Neurosci 11:2489-2497.

Neher E (1986) Concentration profiles of intracellular calcium in the presence of a diffusible chelator. In: Calcium electrogenesis and neuronal functioning: experimental brain research, Series 14. (Heinemann U, Klee M, Neher E, eds), pp 88-96, Berlin: Springer.

Neher E (1995) The use of fura-2 for estimating $\mathrm{Ca}^{2+}$ buffers and $\mathrm{Ca}^{2+}$ fluxes. Neuropharmacology 34:1423-1442.

Neher E, Augustine GJ (1992) Calcium gradients and buffers on bovine chromaffin cells. J Physiol (Lond) 450:273-301.

Nowycky MC, Pinter MJ (1993) Time courses of calcium and calciumbound buffers following calcium influx in a model cell. Biophys $\mathrm{J}$ 64:77-91.

Parker I, Yao Y (1991) Regenerative release of calcium from functionally discrete subcellular stores by inositol triphosphate. Proc R Soc Lond [Biol] 246:269-274.

Parker I, Yao Y (1996) $\mathrm{Ca}^{2+}$ transients associated with openings of inositol triphosphate-gated channels in Xenopus oocytes. J Physiol (Lond) 491:663-668.

Parpura V, Basarsky TA, Liu F, Jeftinija K, Jeftinija S, Haydon PG (1994) Glutamate-mediated astrocyte-neuron signaling. Nature 369:744-747.

Pethig R, Kuhn M, Payne R, Adler E, Chen T-H, Jaffe JF (1989) On the dissociation constants of BAPTA-type calcium buffers. Cell Calcium 10:491-498.

Pozzan T, Tsien R (1989) Measurements of cytosolic free $\mathrm{Ca}^{2+}$ with quin-2. Methods Enzymol 172:230-262.

Regehr WD, Tank DW (1992) Dendritic calcium dynamics. Curr Opin Neurobiol 4:373-382.

Richardson A, Taylor CW (1993) Effects of $\mathrm{Ca}^{2+}$ chelators on purified inositol 1,4,5-triphosphate $\left(\mathrm{InsP}_{3}\right)$ receptors and $\mathrm{InsP}_{3}$-stimulated $\mathrm{Ca}^{2+}$ mobilization. J Biol Chem 268:11528-11533.

Rooney TA, Thomas AP (1993) Intracellular calcium waves generated by $\operatorname{Ins}(1,4,5) \mathrm{P}_{3}$-dependent mechanisms. Cell Calcium 14:674-690.

Sanderson MJ, Charles AC, Boitano S, Dirksen ER (1994) Mechanisms and function of intercellular calcium signaling. Mol Cell Endocrinol 98:173-187.

Smith PD, Liesegang GW, Berger RL, Czerlinsky G, Podolsky RJ (1984) A stopped-flow investigation of calcium ion binding by ethylene glycol bis(b-aminoethyl ether)- $N, N^{\prime}$-tetraacetic acid. Anal Biochem 143:188-195.
Sneyd J, Wetton BTR, Charles AC, Sanderson MJ (1995) Intercellular calcium waves mediated by diffusion of inositol triphosphate: a two dimensional model. Am J Physiol 268:1537-1545.

Spigelman I, Tymianski M, Wallace MC, Carlen PL, Velumian AA (1996) Modulation of hippocampal synaptic transmission by low concentrations of cell-permeant calcium chelators: effects of calcium affinity, structure, and binding kinetics. Neuroscience 75:559-572.

Staros JV, Wright RW, Swingle DM (1986) Enhancement by $N$-hydroxy sulfosuccinimide of water-soluble carbodiimide-mediated coupling reactions. Anal Biochem 156:220-222.

Steinhardt RA, Bi G, Alderton JM (1994) Cell membrane resealing by a vesicular mechanism similar to neurotransmitter release. Science 263:390-393.

Stern MD (1992) Buffering of calcium in the vicinity of a channel pore. Cell Calcium 13:183-192.

Tsien RY (1980) New calcium indicators and buffers with high selectivity against magnesium and protons: design, synthesis, and properties of prototype structures. Biochemistry 19:2396-2404.

Tsien RY (1981) A nondisruptive technique for loading calcium buffers and indicators into cells. Nature 290:527-528.

Tymianski M, Wallace MC, Spigelman I, Uno M, Carlen PL, Tator CH, Charlton MP (1993) Cell permeant $\mathrm{Ca}^{2+}$ chelators reduce early excitotoxic and ischemic neuronal injury in vitro and in vivo. Neuron 11:221-235.

Tymianski M, Charlton MP, Carlen PL, Tator CH (1994) Properties of neuroprotective cell-permeant $\mathrm{Ca}^{2+}$ chelators: effects on $\left[\mathrm{Ca}^{2+}\right]_{\mathrm{i}}$ and glutamate neurotoxicity in vitro. J Neurophysiol 267:1973-1992.

Tymianski M, Bernstein GM, Abdel-Hamid KM, Sattler R, Velumian A, Carlen PL, Razavi H, Jones OT (1997) A novel use for a carbodiimide compound for the fixation of fluorescent and nonfluorescent calcium indicators in-situ following physiological experiments. Cell Calcium 21:175-183.

Venance L, Piomelli D, Glowinski J, Giaume C (1995) Inhibition by anandamide of gap junctions and intercellular calcium signaling in striatal astrocytes. Nature 376:590-594.

Wagner J, Keizer J (1994) Effects of rapid buffers on $\mathrm{Ca}^{2+}$ diff usion and $\mathrm{Ca}^{2+}$ oscillations. Biophys J 67:447-456.

Wang S, Thompson SH (1995) Local positive feedback by calcium in the propagation of intracellular calcium waves. Biophys J 69:1683-1697.

Winslow JL, Duffy SN, Charlton MP (1994) Homosynaptic facilitation of transmitter release in crayfish is not affected by mobile calcium chelators: implications for the residual ionized calcium hypothesis from electrophysiological and computational analyses. J Neurophysiol 72:1769-1793.

Yamamoto N, Yasuda K (1979) Use of a water soluble carbodiimide as a fixing reagent. Acta Histochem Cytochem 10:14-37.

Yao Y, Choi J, Parker I (1995) Quantal puffs of intracellular $\mathrm{Ca}^{2+}$ evoked by inositol triphosphate in Xenopus oocytes. J Physiol (Lond) 482:533-553.

Zhang L, Pennefather P, Velumian A, Tymianski M, Charlton M, Carlen PL (1995) Potentiation of a slow $\mathrm{Ca}^{2+}$-dependent $\mathrm{K}^{+}$current by intracellular $\mathrm{Ca}^{2+}$ chelators in hippocampal CA1 neurons of rat brain slices. J Neurophysiol 74:2225-2241.

Zhou Z, Neher E (1993) Mobile and immobile calcium buffers in bovine adrenal chromaffin cells. J Physiol (Lond) 469:245-273. 